\title{
APLP1 Is a Synaptic Cell Adhesion Molecule, Supporting Maintenance of Dendritic Spines and Basal Synaptic Transmission
}

\author{
Sandra Schilling, ${ }^{1 \star}$ Annika Mehr, ${ }^{2 \star}$ Susann Ludewig, ${ }^{3}$ - Jonathan Stephan, ${ }^{4}$ Marius Zimmermann, ${ }^{1}$ Alexander August, ${ }^{1}$ \\ Paul Strecker, ${ }^{1}$ Martin Korte, ${ }^{3,5}$ Edward H. Koo, ${ }^{6}$ Ulrike C. Müller, ${ }^{2 \star}$ Stefan Kins, ${ }^{1 \star}$ and Simone Eggert ${ }^{1 \star}$ \\ ${ }^{1}$ Department of Human Biology and Human Genetics, University of Kaiserslautern, 67663 Kaiserslautern, Germany, ${ }^{2}$ Institute for Pharmacy and Molecular \\ Biotechnology, University of Heidelberg, 69120 Heidelberg, Germany, ${ }^{3}$ Department of Cellular Neurobiology, TU Braunschweig, Zoological Institute, 38106 \\ Braunschweig, Germany, ${ }^{4}$ Department of Animal Physiology, University of Kaiserslautern, 67663 Kaiserslautern, Germany, ${ }^{5}$ Helmholtz Centre for Infection \\ Research, AG NIND, 38124 Braunschweig, Germany, and ${ }^{6}$ Department of Neuroscience, University of California, San Diego (UCSD), La Jolla, California 92093-0662
}

The amyloid precursor protein (APP), a key player in Alzheimer's disease, belongs to the family of synaptic adhesion molecules (SAMs) due to its impact on synapse formation and synaptic plasticity. These functions are mediated by both the secreted APP ectodomain that acts as a neurotrophic factor and full-length APP forming trans-cellular dimers. Two homologs of APP exist in mammals: the APP like proteins APLP1 and APLP2, exhibiting functions that partly overlap with those of APP. Here we tested whether APLP1 and APLP2 also show features of SAMs. We found that all three family members were upregulated during postnatal development coinciding with synaptogenesis. We observed presynaptic and postsynaptic localization of all APP family members and could show that heterologous expression of APLP1 or APLP2 in non-neuronal cells induces presynaptic differentiation in contacting axons of cocultured neurons, similar to APP and other SAMs. Moreover, APP/APLPs all bind to synaptic-signaling molecules, such as MINT/X11. Furthermore, we report that aged APLP1 knock-out mice show impaired basal transmission and a reduced mEPSC frequency, likely resulting from reduced spine density. This demonstrates an essential nonredundant function of APLP1 at the synapse. Compared to APP, APLP1 exhibits increased trans-cellular binding and elevated cell-surface levels due to reduced endocytosis. In conclusion, our results establish that APLPs show typical features of SAMs and indicate that increased surface expression, as observed for APLP1, is essential for proper synapse formation in vitro and synapse maintenance in vivo.

Key words: Alzheimer's disease; APLP1; APP; APP gene family; synaptic adhesion molecules; synaptogenic activity

Significance Statement

According to the amyloid-cascade hypothesis, Alzheimer's disease is caused by the accumulation of $A \beta$ peptides derived from sequential cleavage of the amyloid precursor protein (APP) by $\beta$-site APP cleaving enzyme 1 (BACE1) and $\gamma$-secretase. Here we show that all mammalian APP family members (APP, APLP1, and APLP2) exhibit synaptogenic activity, involving trans-synaptic dimerization, similar to other synaptic cell adhesion molecules, such as Neuroligin/Neurexin. Importantly, our study revealed that the loss of APLP1, which is one of the major substrates of BACE1, causes reduced spine density in aged mice. Because some therapeutic interventions target APP processing (e.g., BACE inhibitors), those strategies may alter APP/APLP physiological function. This should be taken into account for the development of pharmaceutical treatments of Alzheimer's disease.

\section{Introduction}

The amyloid precursor protein (APP) plays an essential role in Alzheimer's disease (Hardy and Selkoe, 2002), whereas less is known about its physiological function. It is part of a gene family that includes two mammalian homologs, the amyloid precursorlike protein 1 (APLP1) and APLP2 (Muller and Zheng, 2012; Müller et al., 2017). The APP family members show several com- 
mon features, including processing by $\alpha-, \beta$-, and $\gamma$-secretase (Eggert et al., 2004; Li and Südhof, 2004). The type I full-length proteins are first cleaved by sheddases, like $\beta$-site APP cleaving enzyme 1 (BACE1) or $\alpha$-secretase, leading to the release of the large ectodomains [secreted APP (sAPP)/secreted APLP (sAPLP)] and the corresponding membrane-anchored C-terminal fragments (CTFs; Walsh et al., 2007; Tyan and Koo, 2015). They also share a similar domain structure (Coulson et al., 2000). Their large ectodomains include the so called E1 and E2 domains, the first of which is mainly involved in trans-cellular dimerization (Baumkötter et al., 2012). Furthermore, all APP family members contain the YENPTY motif for clathrin-mediated endocytosis in their short C terminus (Jacobsen and Iverfeldt, 2009). Notably, there are also some unique features of APLP1 within the mammalian APP family. APLP1 is exclusively present in neurons (Lorent et al., 1995), whereas APP and APLP2 are expressed ubiquitously (Wasco et al., 1993). For APLP1, only one isoform has been reported (Wasco et al., 1992; Paliga et al., 1997), whereas alternative splicing leads to four mRNA variants for APLP2 (Sandbrink et al., 1996) and eight splice variants for APP (Sandbrink et al., 1994).

APP single-knock-out (KO) mice show reduced body weight (15-20\% reduction) at 9 weeks of age, similar to APLP1 KO mice ( 10\%; Heber et al., 2000). APP/APLP1 double-KO (DKO) mice are viable and fertile, while APP/APLP2 and (Heber et al., 2000) APLP1/APLP2 DKO mice die shortly after birth (Heber et al., 2000), likely due to profound defects at the neuromuscular junction (Wang et al., 2005; Klevanski et al., 2014; Weyer et al., 2014). This underlines the assumption that the APP family members share redundant physiological functions but also have some unique properties.

Interestingly, aged APP KO mice show impairments in spatial learning (Müller et al., 1994; Phinney et al., 1999; Ring et al., 2007), and long-term potentiation (LTP; Seabrook et al., 1999; Ring et al., 2007). Furthermore, a reduced number of dendritic spines (Lee et al., 2010; Tyan et al., 2012) and altered dendritic branching (Tyan et al., 2012; Weyer et al., 2014) have been documented. In contrast, aged APLP2 KO mice (von Koch et al., 1997) show normal spatial learning and no changes in dendritic spine density, dendritic branching, or LTP measurements (Weyer et al., 2011, 2014; Midthune et al., 2012). Analyses of aged APLP1 KO mice have not been performed yet.

Further, in addition to a function of sAPP as a neurotrophic factor (Weyer et al., 2011; Hick et al., 2015; Fol et al., 2016), several independent studies have suggested that APP has a synaptic adhesion molecule (SAM)-like function (Siddiqui and Craig, 2011). Criteria for SAMs include their synaptic localization, functions in cell-cell interaction, and indications for altered synapse formation upon the loss of function of these proteins. Additionally, heterologous expression of SAMs in fibroblasts causes presynaptic differentiations in contacting axons of cocultivated neurons, which has been shown for Neuroligin, Neurexin, leucine-rich repeat transmembranes (LRRTMs), EphB-EphrinB, and Calsyntenin3 (Scheiffele et al., 2000; Biederer et al., 2002; Dean et al., 2003; Kayser et al., 2006; Dalva et al., 2007; Linhoff et al., 2009; Pettem et al., 2013). APP has also been demonstrated to

*S.S. and A.M., the indicated first authors, and U.C.M., S.K., and S.E., the indicated last authors, contributed equally to this work.

The authors declare no competing financial interests.

Correspondence should be addressed to either Stefan Kins or Simone Eggert, Department of Human Biology and Human Genetics, University of Kaiserslautern, Erwin-Schrödinger-Strasse 13, 67663 Kaiserslautern, Germany. E-mail: s.kins@biologie.uni-kl.de or s.eggert@biologie.uni-kl.de or simoneeggert@googlemail.com.

DOI:10.1523/JNEUROSCI.1875-16.2017

Copyright $\odot 2017$ the authors $\quad 0270-6474 / 17 / 375346-21 \$ 15.00 / 0$ induce so called hemisynapses in this coculture assay (Wang et al., 2009; Siddiqui and Craig, 2011; Baumkötter et al., 2014; Stahl et al., 2014). In contrast, synaptogenic functions of APLP1 and APLP2 have not been reported so far. Therefore, we tested whether APLP1 and APLP2 possess key features of SAMs, similar to APPs, including upregulation during synaptogenesis in development, presynaptic and postsynaptic localization, and synaptogenic activity in the mixed coculture assay.

\section{Materials and Methods}

\section{Plasmids}

Cloning of human APLP1 CT HA pcDNA3.1(+). The 300 bp 3'-UTR of APLP1 was amplified from APLP1 wild-type (WT) pBluescript SK ${ }^{+}(\mathrm{Pa}-$ liga et al., 1997) with the sense primer 5'-GTTTATAACTCGAGCCC GGCCCTCTTCAC-3' containing an XhoI site and antisense primer $5^{\prime}$ CCCGCGGCTCTAGAAATTCCAGGGAATAG-3' containing an XbaI site and ligated via the XhoI and XbaI sites in vector pcDNA3.1(+) neo.

A C-terminal HA tag was appended to APLP1 via PCR using the template APLP1 WT in pBluescript $\mathrm{SK}^{+}$(Paliga et al., 1997) and sense primer 5'-GAG CAG AAG GAA CAG AGG CA-3' starting before the APLP1 internal BamHI site and antisense primer 5' -GCTAATCTCGAG TTATGCGTAGTCTGGTACGTCGTACGGATAGGGTCGTTCCTCCA G-3' containing an XhoI site. APLP1 WT in pBluescript $\mathrm{SK}^{+}$was digested by HindIII and BamHI to obtain the N-terminal part of the APLP1 ORF. The 1369 bp HindIII-BamHI fragment was ligated with the BamHI-XhoI fragment via HindIII and XhoI in vector pcDNA3.1(+)neo containing the $3^{\prime}$-UTR of APLP1.

N-terminally myc-tagged APLP2-763 pcDNA3.1(+)zeo was generated by PCR-based cloning. GFP pcDNA3.1(+) has been used before (Stahl et al., 2014). The plasmid mycAPP $\Delta$ CT 648 nt pcDNA3.1(+)neo was generated from the wild-type construct mycAPP695 pcDNA3.1(+) (Soba et al., 2005) via site directed mutagenesis by introducing a stop codon at position 649 of the APP open reading frame (ORF). Myc APP695 pcDNA3.1(+), APLP2-763 HA pcDNA3.1(+), and myc APLP1 pcDNA3.1 $(+)$ have been described previously (Soba et al., 2005).

Cloning of $h X 11 \alpha$ CT Flag pcDNA3.1(+). hX11 $\alpha$ CT myc in pCI neo was cleaved EcoRI to obtain an 1840 bp fragment including the $\mathrm{N}$-terminal part of the hX11 $\alpha$ ORF. A PCR was performed with the template $\mathrm{hX} 11 \alpha \mathrm{CT}$ myc in pCI neo using sense primer $5^{\prime}$-ATG ATC TGC CAC GTC TTC- $3^{\prime}$ starting before the hX11 $\alpha$ internal EcoRI site and the antisense primer $5^{\prime}$-GGT ACC TCT AGA CTA CTT GTC GTC GTC CTT GTA GTC GAT GTA AAC AGG CTG-3' containing the Flag tag sequence and an $\mathrm{XbaI}$ restriction site. The PCR product was cleaved by EcoRI and $\mathrm{XbaI}$ and ligated with the $1840 \mathrm{bp}$ EcoRI fragment via EcoRI and XbaI in vector pcDNA3.1 $(+)$ neo hX11 $\beta$ nt Flag pcDNA3.1 $(+)$ and hX11 $\gamma$ nt Flag pcDNA3.1(+) (Sumioka et al., 2008), which were provided from Professor Toshiharu Suzuki (Hokkaido University, Sapporo, Japan). pNice HA mouse Nlg1 AB was provided by Professor Peter Scheiffele (University of Basel, Switzerland).

\section{Animals}

The generation and genotyping of knock-out lines were described previously [APP KO and APLP1 KO (Heber et al., 2000); APLP2 KO (von Koch et al., 1997)]. All mice have been backcrossed at least six times to C57BL/6 mice. The sex of the species used is of either sex. C57BL/6J mice [embryonic day 14 (E14)] were used for the generation of primary cortical neuron cultures. C57BL/6J mice [postnatal day (P0)] were used for the generation of primary hippocampal neuron cultures.

Mice were treated in accordance with the German law for conducting animal experiments and followed the National Institutes of Health Guide for the Care and Use of Laboratory Animals. Animal housing, breeding, and the sacrifice of mice were approved by the German administration. All experimental protocols were performed in accordance with the European Communities Council Directive of 24 November 1986 (86/609/ EEC). 


\section{Analysis of APP family member protein expression levels in} mouse brains

Mouse cortices of different postnatal stages were homogenized in lysis buffer (50 mu Tris/HCl, pH 7.5; $1 \%$ (v/v) NP-40; 150 mм NaCl; 2 mm EDTA; 1:25 protease inhibitor (complete with EDTA), Roche). After centrifugation for $10 \mathrm{~min}$ at $15,000 \times g$ and $4^{\circ} \mathrm{C}$, the remaining supernatant (cell lysate) was used for further analysis. The protein concentration of cell lysates was determined via BCA assay (Sigma-Aldrich). Twenty micrograms of mouse brain lysates were separated on $8 \%$ Tris/glycine gels. Western blot detection of the APP family members with primary antibodies against the C terminus of APP (Y188; 1:5000; rabbit monoclonal, Abcam), anti-APLP1 (150; 1:2000; rabbit polyclonal; Eggert et al., 2004), anti-APLP1 (57; 1:2000; rabbit polyclonal; Eggert et al., 2004), and anti-APLP2 D2-II (1:5000; rabbit polyclonal; Calbiochem) was followed by incubation with horseradish peroxidase (HRP) coupled secondary antibodies and enhanced chemiluminescence (ECL; Pierce) detection.

Quantification was performed with the program ImageJ. Signals of the APP gene family members were measured and correlated to the signal of the overall protein amount on the nitrocellulose membrane, which was detected via larva purple staining (ServaPurple Stain Solution, Serva; Moritz et al., 2014). Larva purple staining solution was added for $35 \mathrm{~min}$ at room temperature (RT) on PVDF membranes after Western blot transfer. Discoloration of the membrane was followed with $15 \%(\mathrm{v} / \mathrm{v})$ ethanol and $1 \%(\mathrm{v} / \mathrm{v})$ citric acid. The membrane was dried and the fluorescence was detected via imager (Odyssey Fc Dual-mode-imaging System, Li-Cor).

\section{Analysis of APP family member glycosylation in mouse brains}

For deglycosylation, $20 \mu \mathrm{g}$ of mouse brain lysates were treated with $O^{\prime}$ glycosidase, EndoH, and PNGase F (New England BioLabs) according to manufacturer instructions. After incubation for $1 \mathrm{~h}$ at $37^{\circ} \mathrm{C}$, the samples were shortly centrifuged and then denatured in $4 \times$ SDS sample buffer [0.25 м Tris/HCl, pH 6.8; 40\% (w/v) glycerol; 8\% (w/v) SDS; $0.02 \%$ (w/v) Bromophenol Blue; $200 \mathrm{~mm}$ DTT]. Equal amounts of protein were separated on $8 \%$ Tris/glycine gels. Western blot detection of the APP family members was performed with primary antibodies, as described above.

\section{Synaptosomal preparation and enrichment of the postsynaptic density}

Samples were always kept on ice, and all centrifugation steps were performed at $4^{\circ} \mathrm{C}$. One mouse brain was homogenized in solution $\mathrm{A}(0.32 \mathrm{M}$ sucrose; $1 \mathrm{~mm} \mathrm{NaHCO} ; 11 \mathrm{~mm} \mathrm{MgCl} ; 0.5 \mathrm{~mm} \mathrm{CaCl}_{2}$ ) by a Potter $\mathrm{S}$ Homogenizer. Centrifugation for $10 \mathrm{~min}$ at $800 \times \mathrm{g}$ sedimented crude cell fragments ["post-nuclear supernatant" (Post ns)]. The supernatant was centrifuged for $15 \mathrm{~min}$ at $9000 \times g$ (smaller cell components stay in the supernatant). The pellet was resuspended in solution A, centrifuged again for $15 \mathrm{~min}$ at $10,000 \times \mathrm{g}$, and resuspended in solution $\mathrm{B}(0.32 \mathrm{M}$ sucrose; $1 \mathrm{~mm} \mathrm{NaHCO}_{3}$ ) to obtain a raw synaptosomal fraction (Syn crude). Synaptosomal membranes were isolated via hypo osmotic shock by the addition of double-distilled water. The reaction was stopped with 0.5 м HEPES/NaOH, pH 7.4 [fraction "synaptosomes after hypoosmotic shock" (Syn hyp)]. The solution was centrifuged for $20 \mathrm{~min}$ at $25,000 \times g$, and the pellet was subsequently (dissolved in solution B) loaded on a sucrose gradient $\left(0.5 \mathrm{~m} ; 1 \mathrm{M} ; 2 \mathrm{M}\right.$ sucrose in $\left.1 \mathrm{~mm} \mathrm{NaHCO}{ }_{3}\right)$. A discontinuous density centrifugation at $83,500 \times g$ was performed for $3 \mathrm{~h}$. The high dense fraction was collected (Syn total) and treated with $2 \times$ LP-buffer (0.32 м sucrose; $12 \mathrm{~mm}$ Tris/ $\mathrm{HCl} \mathrm{pH} \mathrm{8.0;1 \%} \mathrm{(v/v)} \mathrm{Triton}$ $\mathrm{X}-100 ; 1 \mathrm{~mm} \mathrm{NaHCO}$ ). Triton X-100 denatured all proteins of the presynapse, while only the postsynaptic density (PSD) stays intact. A further ultracentrifugation step at $201,800 \times g$ for 20 min pelleted the PSD, which was subsequently resuspended in $5 \mathrm{~mm}$ Tris/ $\mathrm{HCl}$. To analyze equal amounts of proteins, a BCA test was performed and the samples were loaded on an $8 \%$ Tris/glycine gel. The following primary antibodies were used for Western blot detection: PSD-95 (1:2000; mouse monoclonal, Abcam); synaptophysin (1:2000; mouse monoclonal, Sigma-Aldrich); anti-APP C terminus (1:5000; Y188, rabbit monoclonal, Abcam); antiAPLP1 (57, 1:2000, rabbit polyclonal; Eggert et al., 2004); anti-APLP2 (1:1000, rabbit polyclonal; CT12, Calbiochem) followed by secondary antibodies, which were coupled to HRP for detection after Western blotting with ECL (Pierce).

\section{Optical and sciatic nerve preparations}

The optical and sciatic nerves were dissected from adult C57BL/6J mice and adult APP KO, APLP1 KO, and APLP2 KO mice. The species studied was of either sex. Sciatic nerves of three mice were collected in $5 \times$ volume homogenization buffer (10 mM HEPES, pH 7.3; 1 mM EDTA, pH 8.0; 250 $\mu \mathrm{M}$ saccharose, $\mathrm{pH}$ 7.5; Complete Protease Inhibitor, Roche) in a $1.5 \mathrm{ml}$ Eppendorf tube and homogenized mechanically via a micropistil. The homogenate was centrifuged at $1000 \times g$, and the supernatant was subsequently used for analysis after a BCA assay (Sigma-Aldrich) was performed. Optic nerve preparations were performed according to a protocol from Berg et al. (2000).

\section{Preparation and immunocytochemical staining of transfected primary hippocampal neurons}

The hippocampi were dissected from P0-P1 C57BL/6J mice. Preparation of hippocampal neurons followed as described previously (Tyan et al., 2012). After washing three times with buffer $\left[\mathrm{Ca}^{2+} / \mathrm{Mg}^{2+}\right.$-free HBSS with $1 \%(\mathrm{v} / \mathrm{v})$ penicillin/streptomycin (Pen/Strep) and $1 \%(\mathrm{w} / \mathrm{v}) \mathrm{D}$-glucose], the hippocampi were incubated for $15 \mathrm{~min}$ at $37^{\circ} \mathrm{C}$ with $0.05 \%$ trypsinEDTA. After centrifugation for $5 \mathrm{~min}$ at $447 \times g$, the hippocampi were resuspended in suspend solution (50\% Ham's F-12 and 50\% DMEM with $1 \%$ Pen/Strep and $0.1 \%$ DNAseI) and triturated with a long transfer pipette up to 50 times. Afterwards, the suspension was passed through a disposable cell strainer (70 $\mu \mathrm{M}$ nylon, Falcon). After a further centrifugation step, the neurons were resuspended in growth media [Neurobasal Media with $1 \%(\mathrm{v} / \mathrm{v})$ sodium pyruvate, $1 \%(\mathrm{v} / \mathrm{v})$ Pen/Strep, $2 \mathrm{~mm}$ L-glutamine, and $2 \%(\mathrm{v} / \mathrm{v})$ B-27 supplement]. The cells were plated on coverslips (14 mm; Marienfeld) that had been coated with poly-L-lysine in borate buffer previously.

The neurons were transfected on day in vitro 7 (DIV7) via Ca/Pi (Tyan et al., 2012) with APP695 HA pcDNA 3.1(+), APLP1 HA pcDNA 3.1(+), and APLP2-763 HA pcDNA 3.1(+). After 18-22 h, the neurons were fixed for $10 \mathrm{~min}$ at $37^{\circ} \mathrm{C}$ in $4 \%(\mathrm{w} / \mathrm{v})$ PFA with $4 \%(\mathrm{w} / \mathrm{v})$ sucrose and permeabilized for $10 \mathrm{~min}$ with $0.1 \%(\mathrm{v} / \mathrm{v}) \mathrm{NP}-40$. The APP gene family members were visualized via antibody HA [1:300; rat monoclonal $(3 F 10)$, Roche). Dendrites were stained with an anti-microtubuleassociated protein 2 (MAP2) antibody (1:300; rabbit polyclonal, Santa Cruz Biotechnology) and axons by an anti-Taul antibody (1:200; mouse monoclonal, Millipore Bioscience Research Reagents). Secondary antibodies were Alexa Fluor 488, Alexa Fluor 594, and Alexa Fluor 647 (1: 1000; Invitrogen). Imaging was performed with an Axio Observer Z.1 Microscope (with apotome; Zeiss) and $z$-stacks were taken in $0.200 \mu \mathrm{M}$ steps.

The same procedure was performed with DIV7 fixed cortical neurons to analyze endogenous localization of the APP gene family members in axons and dendrites [for preparation of neurons, see Coculture assay (hemisynapse assay)]. For visualization, antibodies anti-APP C terminus (1:5000; Y188, rabbit monoclonal, Abcam), anti-APLP1 C terminus (1: 1000; CT-11, rabbit polyclonal, Calbiochem), and anti-APLP2 C terminus (1:1000; CT-12, rabbit polyclonal, Calbiochem) were used.

\section{Coculture assay (hemisynapse assay)}

The synaptogenic activity of the APP gene family members was analyzed using a coculture assay with HEK293T (HEK) cells and primary cortical neurons (Scheiffele et al., 2000; Biederer and Scheiffele, 2007; Stahl et al., 2014). HEK293T cells were cultured in DMEM with 10\% FBS and $1 \%$ Pen/Strep. The primary cortical neurons were prepared on E14 from C57BL/6J mice. The cortices were dissociated with a fire-polished Pasteur pipette after incubation for $15 \mathrm{~min}$ at $37^{\circ} \mathrm{C}$ in $0.05 \%$ Trypsin-EDTA and washing five times with ice-cold HBSS supplemented with $10 \mathrm{~mm}$ HEPES. The isolated neurons were resuspended in DB1 media [DMEM with $10 \%$ (v/v) FCS, $0.79 \%$ (w/v) D-glucose, and $2 \mathrm{~mm} \mathrm{L-glutamine],} \mathrm{and}$ $140,000 \mathrm{cells} / \mathrm{ml}$ (500 $\mu \mathrm{l} /$ coverslip) were seeded on $14 \mathrm{~mm}$ coverslips (Marienfeld) pretreated with poly-L-lysine in borate buffer $(20 \mu \mathrm{g} / \mathrm{ml})$. After $6 \mathrm{~h}$ of incubation, the media were replaced by NM media [Neurobasal media with $2 \%(\mathrm{v} / \mathrm{v})$ B-27 supplement and $2 \mathrm{~mm}$ glutamate]. At DIV6 of the neuronal culture, HEK293T cells were transiently trans- 
fected with jetPRIME (Polyplus). GFP pcDNA3.1(+) was used as a negative control, and $\mathrm{Nlg} 1 \mathrm{HA} \mathrm{pcDNA3.1(+)}$ was used as a positive control. The constructs for the APP gene family, APP695 HA pcDNA3.1 $(+)$, APLP1 HA pcDNA3.1(+), APLP2-763 HA pcDNA3.1(+), were also analyzed. Twenty-four hours after transfection, the HEK cells were seeded on the neuronal culture at a density of 400,000 cells/coverslip. After a coculture time of $24 \mathrm{~h}$, the cells were fixed for $10 \mathrm{~min}$ at $37^{\circ} \mathrm{C}$ in $4 \%(\mathrm{w} / \mathrm{v})$ PFA with $4 \%(\mathrm{w} / \mathrm{v})$ sucrose and washed three times with $1 \times$ PBS. Subsequently, an immunocytochemical staining was performed. The cells were permeabilized with $0.1 \% \mathrm{NP}-40$ in $1 \times \mathrm{PBS}$ for $10 \mathrm{~min}$ and blocked in $5 \%$ goat serum in $1 \times$ PBS. The overexpressed proteins were visualized with an antibody against their HA tag (1:300; rat monoclonal (3F10), Roche) followed by an Alexa Fluor 488-conjugated secondary antibody (1:1000; Invitrogen). For detection of a presynaptic marker, an antibody against synaptophysin (1:200, mouse monoclonal antibody, Sigma-Aldrich; secondary antibody Alexa Fluor 594 conjugated) was used. Synaptophysin staining was the readout of the assay. The synaptophysin puncta at the HEK cells were taken as an indication for presynaptic differentiation in the contacting neuron. For quantification, the number of synaptophysin puncta per cell was counted and the area that was covered by these puncta was determined. To avoid false-positive puncta, the assay was costained with an antibody against MAP2 (1:300; rabbit polyclonal, Santa Cruz Biotechnology; secondary antibody Alexa Fluor 647 conjugated). Only cells that did not contact MAP2-stained dendrites were chosen for quantification to ensure that only so-called hemisynapses between an HEK293T cell and an axon were analyzed. For the staining of axons, an anti-Taul antibody (1:200; mouse monoclonal, Millipore Bioscience Research Reagents) was used. The z-stack images were taken with the Axio Observer Z.1 Microscope (with apotome; Zeiss), and quantification was performed via ImageJ analysis. Statistical analysis was performed using one-way ANOVA followed by Tukey's post hoc test $\left(n \geq 4 ;{ }^{*} p<0.05 ;{ }^{* *} p<0.01 ;{ }^{* *} p<0.001\right)$. To assess whether APLP1 synaptogenic activity depends on endogenous expression of APP family members, $\mathrm{APP}^{+/-}$APLP2 ${ }^{-1-}$ heterozygous matings were set up to obtain $\mathrm{APP}^{-1-} \mathrm{APLP}^{-1-} \mathrm{DKO}$ neurons and internal APLP2 ${ }^{-1-}$ single-KO littermate (LM) controls. APLP1 KO and wild-type neurons were obtained from APLP1 ${ }^{+/-}$matings.

\section{Cell culture and purification of APPex-crystallizable fragment} and APLPex-crystallizable fragment

COS-7 cells were stably transfected with APPex-crystallizable fragment $\left(\mathrm{F}_{\mathrm{C}}\right), \mathrm{APLP} 1 \mathrm{ex}-\mathrm{F}_{\mathrm{C}}$, or APLP2ex- $\mathrm{F}_{\mathrm{C}}$. The fusion protein consists of the ectodomain of APP, APLP1, or APLP2 fused to the $\mathrm{F}_{\mathrm{C}}$ of human IgG1. The cells were cultured in DMEM containing 10\% FBS, the selection antibiotic (Hygromycin B) and penicillin/streptomycin. Conditioned medium of COS-7 cells transfected with APPex- $\mathrm{F}_{\mathrm{C}}$ or COS-7 APLP1ex- $\mathrm{F}_{\mathrm{C}}$ was collected $3 \mathrm{~d}$ after seeding. Cells expressing APLP2ex- $\mathrm{F}_{\mathrm{C}}$ were cultured in FBS-containing medium until confluency reached $100 \%$. Afterwards, the medium was replaced by serum-free medium, conditioned for $24 \mathrm{~h}$, and collected. The conditioned medium was sterile filtered $(0.45 \mu \mathrm{m}$ Bottle Top Filtration Unit, VWR), and binding buffer was added (50 mM Tris/HCl, $300 \mathrm{~mm} \mathrm{NaCl}, \mathrm{pH}$ 7.4). APLP2ex- $\mathrm{F}_{\mathrm{C}}$ was purified by affinity chromatography using a protein A Sepharose FF $20 \mathrm{ml}$ affinity column (GE Healthcare). After the medium was loaded on the column, it was washed with binding buffer until UV absorption reached baseline levels, and the bound proteins were eluted by adding $100 \mathrm{~mm}$ glycine, $\mathrm{pH} 2.5$. Immediately after elution, $1 \mathrm{M}$ Tris/ $\mathrm{HCl}, \mathrm{pH} 8.0$, was added to restore the $\mathrm{pH}$, and the protein was concentrated and desalted using a PD-10 desalting column (GE Healthcare). For purification of $A P P e x-F_{C}$ and APLP1ex $-\mathrm{F}_{\mathrm{C}}$, the medium was first loaded on the protein A Sepharose column, analogous to the purification of APLP2ex- $\mathrm{F}_{\mathrm{C}}$. Additionally, affinity chromatography of the eluted protein from the protein A column was performed using a HiTrap Heparin HP $5 \mathrm{ml}$ affinity column (GE Healthcare) to remove antibodies present in the FBS. After loading the sample on the column, it was washed with $20 \mathrm{~mm}$ HEPES and $150 \mathrm{~mm}$ $\mathrm{NaCl}, \mathrm{pH}$ 7.2, until UV absorption reached baseline. The protein was eluted using $20 \mathrm{~mm}$ HEPES and $1 \mathrm{M} \mathrm{NaCl}, \mathrm{pH}$ 7.2. The purity of the sample was examined by SDS-PAGE, and protein concentration was determined via measurement at $280 \mathrm{~nm}$ (NanoDrop).

\section{Bead aggregation assay}

To analyze the dimerization properties of APPex $-\mathrm{F}_{\mathrm{C}}, \mathrm{APLP} 1 \mathrm{ex}-\mathrm{F}_{\mathrm{C}}$, and APLP2 ex- $\mathrm{F}_{\mathrm{C}}, 10 \mu$ l of magnetic protein A-coated polystyrene beads (Invitrogen) were incubated with $15 \mu \mathrm{g}$ protein for $2 \mathrm{~h}$ at $4^{\circ} \mathrm{C}$ via end-overend rotation. Afterwards, the beads were washed three times with binding buffer (20 mм HEPES, $150 \mathrm{~mm} \mathrm{NaCl}$, pH 7.2). Subsequently, 400 $\mu \mathrm{l}$ of binding buffer containing $0.1 \%$ BSA and $400 \mu \mathrm{l}$ of $3 \mathrm{~d}$ conditioned COS-7 wild-type medium was added to the beads. The beads were sonicated to singularize them and incubated for $2 \mathrm{~h}$ at $4^{\circ} \mathrm{C}$ with end-over-end rotation. For measurements, $200 \mu \mathrm{l}$ of the suspension was diluted in 10 $\mathrm{ml}$ of Isoton II, and aggregates with a diameter of $>10 \mu \mathrm{m}$ were counted on a Beckman Coulter Z2 Counter.

\section{Analysis of proteolytic processing}

HEK293T cells were transiently transfected at a confluency of 70\% with jetPRIME (PolyPlus) according to manufacturer instructions with APP NT myc pcDNA3.1 $(+)$, APLP1 NT myc pcDNA3.1 $(+)$, and APLP2 NT myc pcDNA3.1(+), or APP CT HA pcDNA3.1 $(+)$, APLP1 CT HA pcDNA3.1 $(+)$, and APLP2 CT HA pcDNA3.1 $(+)$. The media were conditioned for $2 \mathrm{~h}$ ( $1 \mathrm{ml}$ of media in one well of a 6 -well plate). The cells were harvested and lysed in $200 \mu$ lysis buffer [ $50 \mathrm{~mm}$ Tris/HCl, pH 7.5; 150 mм NaCl; 5 mм EDTA; 1\% NP-40; 1:25 Complete Protease Inhibitor (with EDTA), Roche] for $20 \mathrm{~min}$. Cell debris was pelleted at $15,700 \times g$ for $10 \mathrm{~min}$ at $4^{\circ} \mathrm{C}$. For analysis of the CTFs, the same amounts of protein were loaded on a $4-12 \%$ Bis-Tris gel (Invitrogen). APP, APLP1, and APLP2 full-length proteins as well as their C-terminal fragments were detected via antibody HA [1:5000; rat monoclonal (3F10), Roche]. To investigate shedding of the APP family members, cell lysates as well as conditioned media were separated on an $8 \%$ Tris/glycine gel and visualized via their myc tag (1:1000; rabbit polyclonal, Santa Cruz Biotechnology) followed by secondary antibodies, which are coupled to HRP for detection after Western blotting with ECL (Pierce). Images were analyzed via ImageJ, and the ratio between CTF or secreted proteins and full-length proteins was quantified. Statistical analysis of CTFs was performed using a Kruskal-Wallis test followed by Dunn's multiplecomparison test with Bonferroni's correction $\left(n=4\right.$; ${ }^{\star} p<0.05 ;{ }^{* \star} p<$ $0.001 ;{ }^{* *} p<0.0001$; bars represent the mean \pm SEM). Statistical analysis for the secreted fragment was performed using a Kruskal-Wallis test followed by Dunn's multiple-comparison test with Bonferroni's correction $\left(n=7 ;{ }^{\star} p<0.05 ;{ }^{* *} p<0.01 ;{ }^{* *} p<0.001\right.$; bars represent the mean \pm SEM).

\section{Antibody uptake assay}

N2a cells were cultured in MEM media with 10\% (v/v) FBS, 1\% (v/v) Pen/Strep, $1 \%(\mathrm{v} / \mathrm{v})$ nonessential amino acids, $1 \%(\mathrm{v} / \mathrm{v})$ sodium pyruvate, and $2 \mathrm{~mm}$ L-glutamine. A total of 70,000 cells were plated per $14 \mathrm{~mm}$ coverslip (Marienfeld) in a 24-well plate that had been coated with polyL-lysine in double-distilled $\mathrm{H}_{2} \mathrm{O}$. The cells were transfected the following day with jetPRIME (PolyPlus) according to manufacturer instructions with APP NT myc pcDNA3.1(+), APLP1 NT myc pcDNA3.1(+), APLP2 NT myc pcDNA3.1(+), and APP $\Delta$ CT 648 NT myc pcDNA3.1(+), which served as a negative control. Seventeen to $24 \mathrm{~h}$ after transfection, the cells were placed on ice to stop endocytosis. After washing with OptiMEM (Invitrogen), the cells were incubated for $30 \mathrm{~min}$ with the primary antibody c-myc (1:200; 9E10, mouse monoclonal, Abcam) against the myc tag of the transfected APP family proteins. The cells were washed with OptiMEM again to remove the unbound antibody. Subsequently, endocytosis was allowed at $37^{\circ} \mathrm{C}$ for different time points in prewarmed N2a growth media. Afterwards, the cells were cooled down again to $4^{\circ} \mathrm{C}$ and fixed with $4 \%(\mathrm{w} / \mathrm{v})$ PFA with $4 \%(\mathrm{w} / \mathrm{v})$ sucrose. After permeabilization for 10 min with $0.1 \%(\mathrm{v} / \mathrm{v}) \mathrm{NP}-40$ in $1 \times \mathrm{PBS}$, the cells were blocked in $5 \%$ $(\mathrm{v} / \mathrm{v})$ goat serum in $1 \times$ PBS and incubated with Alexa Fluor 594conjugated secondary antibody (1:400; Invitrogen) to stain the remaining APP/APLPs at the cell surface and the internalized protein. After a further washing step with $1 \times$ PBS, the coverslips were embedded in Mowiol. The z-stack images were taken with the Axio Observer Z.1 Microscope (with apotome; Zeiss). Projections of these stacks were performed with the program ImageJ. For each construct and time point, the amount of endocytosed protein was determined by measuring the inten- 
sity of the internalized protein and the intensity of the surface protein. The ratio of the endocytosed protein to total intensities (internalized plus cell surface protein) represents the amount of endocytosed protein per cell. Statistical analysis was performed using one-way ANOVA followed by Tukey's post hoc test $\left(n=4 ;{ }^{*} p<0.05 ;{ }^{* *} p<0.01\right.$; ${ }^{* *} p<0.001$; bars represent the mean $\pm \mathrm{SEM})$.

\section{Coimmunoprecipitation}

N2a cells (growth media see above) were transiently cotransfected (jetPRIME) with a CT HA-tagged APP gene family member and one member of the X11 family [X11 $\alpha$ CT Flag pcDNA3.1(+), X11 $\beta$ NT Flag pcDNA3.1 $(+)$, or X11 $\gamma$ NT Flag pcDNA3.1(+)]. After 17-24 h, the cells were harvested and lysed (see above). Equal volumes of cell lysates containing $800 \mu \mathrm{g}$ of protein were precleared with $10 \mu \mathrm{l}$ of protein A Sepharose (GE Healthcare) for $1 \mathrm{~h}$ at $4^{\circ} \mathrm{C}$. After centrifuging the beads for 2 $\min$ at $2000 \times g$ at $4^{\circ} \mathrm{C}$, the supernatant was incubated for $2-3 \mathrm{~h}$ with 20 $\mu l$ of HA beads (Roche) at RT. Afterwards, the beads were washed three times with $750 \mu$ l lysis buffer $[50 \mathrm{~mm}$ Tris/ $\mathrm{HCl}$, pH 7.5; $150 \mathrm{~mm} \mathrm{NaCl} ; 5$ mм EDTA; 1\% NP-40; 1:25 Complete Protease Inhibitor (with EDTA), Roche)] and sedimented for $2 \mathrm{~min}$ at $2000 \times \mathrm{g}$. A last washing step was performed with $10 \mathrm{~mm}$ Tris/ $\mathrm{HCl}, \mathrm{pH}$ 7.5. The supernatant was completely removed, and the beads were resuspended in $2 \times$ SDS sample buffer $(0.125$ м Tris/HCl, pH 6.8; $20 \%$ glycerol; 4\% SDS; $0.01 \%$ Bromophenol Blue; $100 \mathrm{~mm}$ DTT). The samples were denatured for $5 \mathrm{~min}$ at $95^{\circ} \mathrm{C}$ and loaded onto an $8 \%$ Tris/glycine gel. After Western blotting, the X11 family members were detected with an anti-Flag antibody (1:5000; Sigma-Aldrich). Afterwards, the same membrane was incubated with antibody HA (1:5000; 3F10 rat monoclonal antibody, Roche) to detect immunoprecipitated (IP) APP gene family members. Direct loads of the cell lysates were visualized with the same antibodies as the IP samples.

\section{Cell surface biotinylation}

A total of $5 \times 10^{5}$ HEK293T cells were seeded on a 6-well plate. The following day the cells were transiently transfected with JetPrime with APP CT HA pcDNA3.1(+), APLP1 CT HA pcDNA3.1(+), or APLP2 CT HA pcDNA3.1 $(+)$. After 17-24 h, the cells were rinsed twice with icecold $1 \times$ PBS and incubated for $30 \mathrm{~min}$ at $4^{\circ} \mathrm{C}$ with $1 \mathrm{ml}$ of EZ-Link Sulfo-NHS-LC-Biotin ( $2 \mathrm{mg} / \mathrm{ml}$; Pierce) in ice-cold PBS to biotinylate surface proteins. To quench unconjugated biotin, the cells were washed three times with $1 \times \mathrm{PBS}$ supplemented with $100 \mathrm{~mm}$ glycine. Cells were lysed in $1 \times$ RIPA buffer [20 mм Tris/HCl, pH 8.0; $150 \mathrm{~mm} \mathrm{NaCl;} 1 \%$ NP-40 (w/v); 0.5\% deoxycholate; 5 mM EDTA, pH 8.0; 0.1\% SDS; 1:25 Complete Protease Inhibitor (with EDTA), Roche)], and $20 \mu \mathrm{g}$ of lysate were used for the direct load. Equal protein amounts were incubated with NeutrAvidin Agarose Resin (Pierce) overnight at $4^{\circ} \mathrm{C}$. On the following day, the beads were washed with RIPA buffer and boiled at $95^{\circ} \mathrm{C}$ for $5 \mathrm{~min}$ in $2 \times$ sample buffer with DTT to recover the biotinylated proteins. Direct load and surface proteins were separated on an $8 \%$ Tris/glycine gel and detected with antibody HA (1:5000; 3F10 rat monoclonal antibody, Roche; Stahl et al., 2014).

\section{Golgi-Cox staining}

Golgi staining of APLP1 KO mice and wild-type littermates was performed using the Rapid Golgi Staining Kit (FD NeuroTechnologies) according to manufacturer instructions. The $2.5 \mathrm{ml}$ kit solutions A and $\mathrm{B}$ were mixed and incubated at RT for 2-3 h. Both hemispheres of each mouse were immersed in $2.5 \mathrm{ml}$ of the mixture with equal parts of kit solutions A and B and were stored at RT for $24 \mathrm{~h}$. The remaining impregnation solution was added, and hemispheres were stored at RT for 2 weeks. Afterwards, brain tissues were transferred into solution $\mathrm{C}$ and incubated at RT for $72 \mathrm{~h}$ or up to $7 \mathrm{~d}$ before sectioning. Solution $\mathrm{C}$ was renewed after $24 \mathrm{~h}$. Coronal brain sections $(100 \mu \mathrm{m})$ from $4 \%$ PFA-fixed mouse brains were cut using a vibratome (VT1000S, Leica). Each section was mounted with solution $\mathrm{C}$ on an adhesive microscope slide precoated with poly L-lysine (Thermo Scientific) and stained according to the manufacturer protocol, except that Roticlear (Carl Roth) was used instead of xylene. Finally, slides were embedded with Entellan (Merck Millipore).

Images of hippocampal CA1 pyramidal neurons were obtained on an AxioObserver Z1 Microscope (Zeiss) with a $63 \times$ oil-objective and a $z$-stack distance of $0.5 \mu \mathrm{m}$ under reflected light. The number of spines per micrometer of dendritic length (in total, $100 \mu \mathrm{m}$ ) was determined in second- or third-order dendritic branches of apical dendrites in midapical regions of the stratum radiatum (apical compartment) using Neurolucida software (MicroBrightField). Only dendrites of similar diameter were used for spine density measurements. Basal dendrites of similar thickness within the stratum oriens were at least $20 \mu \mathrm{m}$ from the soma. At minimum, five animals per genotype and eight neurons per animal were imaged and analyzed blind to genotype.

Golgi-Cox stainings were analyzed using GraphPad Prism (version 6) software. Spine density is expressed as the mean \pm SEM. Differences between genotypes were detected with unpaired Student's $t$ test (two-tailed).

\section{Immunohistochemistry}

Briefly, 13-month-old APLP1 KO mice and LM controls were perfused in PBS and 4\% PFA in $1 \times$ PBS. The $30 \mu \mathrm{m}$ slices (frozen sections) were analyzed. Synaptophysin antibody (guinea pig, Synaptic Systems) was used as a primary antibody (1:300), and Alexa Fluor 488 was used as a secondary antibody (Kullmann et al., 2011).

\section{Preparation of acute hippocampal slices for LTP measurements}

In vitro extracellular recordings were performed on acute hippocampal slices of WT littermates and APLP1 KO animals $(N=5)$. Between recordings, animals were housed in a temperature- and humiditycontrolled room with a $12 \mathrm{~h}$ light/dark cycle and had access to food and water ad libitum. The experimental protocols were performed in accordance with the European Communities Council Directive of 24 November 1986 (86/609/EEC).

Acute hippocampal transversal slices were prepared from individuals at an age of 4-6 months (young mice cohort) or 11-13 months (aged cohort). Mice were anesthetized with isoflurane and decapitated. The brain was removed and quickly transferred into ice-cold carbogenated $\left(95 \% \mathrm{O}_{2}, 5 \% \mathrm{CO}_{2}\right)$ artificial CSF (ACSF) containing $125.0 \mathrm{~mm} \mathrm{NaCl}, 2.0$ mм KCl, $1.25 \mathrm{~mm} \mathrm{NaH}_{2} \mathrm{PO}_{4}, 2.0 \mathrm{~mm} \mathrm{MgCl}, 26.0 \mathrm{~mm} \mathrm{NaHCO}, 2.0 \mathrm{~mm}$ $\mathrm{CaCl}_{2}$, and $25.0 \mathrm{~mm}$ glucose. The hippocampus was sectioned into 400$\mu \mathrm{m}$-thick transversal slices with a vibratome (VT1200S, Leica) and maintained in carbogenated ACSF at room temperature for at least $1.5 \mathrm{~h}$ before being transferred into a submerged recording chamber.

Slices were placed in a submerged recording chamber and perfused with carbogenated ACSF $\left(32^{\circ} \mathrm{C}\right)$ at a rate of $1.2-1.5 \mathrm{ml} / \mathrm{min}$. Field EPSPs (fEPSPs) were recorded in stratum radiatum of CA1 region with a borosilicate glass micropipette (resistance, $2-5 \mathrm{M} \Omega$ ) filled with $3 \mathrm{M} \mathrm{NaCl}$ at a depth of $\sim 150-200 \mu \mathrm{m}$. Monopolar tungsten electrodes were used for stimulating the Schaffer collaterals at a frequency of $0.1 \mathrm{~Hz}$. Stimulation intensity was adjusted to $\sim 40 \%$ of maximum fEPSP slope for $20 \mathrm{~min}$ of baseline recording. LTP was induced by applying theta-burst stimulation (TBS; 10 trains of four pulses at $100 \mathrm{~Hz}$ in a $200 \mathrm{~ms}$ interval, repeated three times) and recorded for $60 \mathrm{~min}$.

Basal synaptic transmission properties were analyzed via input-output (IO) measurements, and short-term plasticity was examined via paired-pulse facilitation (PPF). The IO measurements were performed either by the application of defined current values $(25-250 \mu \mathrm{A})$ or by adjusting the stimulus intensity to certain fiber volley (FV) amplitudes (0.1-0.8 mV). PPF was performed by applying a pair of two closely spaced stimuli in different interstimulus intervals ranging from 10 to $160 \mathrm{~ms}$.

\section{Preparation of acute hippocampal slices for measuring} miniature EPSCs

Acute coronal hippocampal slices were prepared from an aged cohort of APLP1 KO mice and wild-type littermates (age, 12-13 months). Animals were decapitated, and the brains were quickly dissected in ice-cold cutting solution containing the following (in mM): $93 \mathrm{~N}$-methyl-Dglucamin, $93 \mathrm{HCl}, 30 \mathrm{NaHCO}_{3}, 1.2 \mathrm{NaH}_{2} \mathrm{PO}_{4}, 20$ HEPES, $2.5 \mathrm{KCl}, 10$ $\mathrm{MgCl}_{2}, 0.5 \mathrm{CaCl}_{2}, 25$ D-glucose, 3 Na-pyruvate, 3 myoinositol, and 5 ascorbic acid. Thereafter, $300-\mu \mathrm{m}$-thick slices were obtained using a vibratome (VT1200 S, Leica; HM650V Microtome, Microm International). After sectioning, slices were incubated for $10-12 \mathrm{~min}$ at $37^{\circ} \mathrm{C}$ in the same solution. Thereafter, slices were transferred to ACSF containing the following (in mM): $125 \mathrm{NaCl}, 25 \mathrm{NaHCO}_{3}, 1.25 \mathrm{NaH}_{2} \mathrm{PO}_{4}, 2.5 \mathrm{KCl}, 1$ $\mathrm{MgCl}_{2}, 2 \mathrm{CaCl}_{2}, 10$ D-glucose, $2 \mathrm{Na}$-pyruvate, 3 myoinositol, and 0.44 ascorbic acid, pH 7.4, bubbled with carbogen $\left(95 \% \mathrm{O}_{2}, 5 \% \mathrm{CO}_{2}\right)$. Finally, 
slices were held for $60 \mathrm{~min}$ at RT $\left(20-24^{\circ} \mathrm{C}\right)$ to recover from cutting. To allow for unbiased subsequent patch-clamped recordings, experiments were performed and analyzed blind. Thus, mouse tails were taken for post hoc genotyping. Chemicals were purchased from Sigma-Aldrich or AppliChem, if not stated otherwise.

We used the patch-clamp technique to record miniature EPSCs (mEPSCs) from pyramidal neurons in the hippocampal CA1 region. The recording chamber was placed at an upright microscope equipped with infrared differential interference contrast $(60 \times$ water-immersion objective, 1.0 numerical aperture; Eclipse FN1, Nikon) and an infrared video camera (XC-ST70CE, Hamamatsu). Whole-cell recordings were performed using a double-patch-clamp EPC10 amplifier and "PatchMaster" software (HEKA Electronic). The pipette solution contained the following (in mM): $140 \mathrm{~K}$-gluconate, 5 EGTA, $10 \mathrm{HEPES}, 1 \mathrm{MgCl}_{2}, 2 \mathrm{Na}_{2} \mathrm{ATP}$, and $0.3 \mathrm{Na}_{2} \mathrm{GTP}, \mathrm{pH}$ 7.30. Pipettes were pulled from borosilicate glass capillaries [GB150(F)-8P, [Science Products]] using a horizontal puller (P-87, Sutter Instruments) and had a resistance of $\sim 7-8 \mathrm{M} \Omega$. For mEPSC recordings, patched neurons were clamped to $-70 \mathrm{mV}$ and continuously perfused with $0.5 \mu \mathrm{M}$ TTX (Biotrend) in ACSF to avoid contamination of recordings by spontaneous neuronal activity. Voltageclamp recordings were sampled at $20 \mathrm{kHz}$ and filtered at $2.9 \mathrm{kHz}$. Data were processed and analyzed using IGOR Pro 6.2 Software (WaveMetrics) and MiniAnalysis version 6.0.3 Software (Synaptosoft). Data were analyzed using WinSTAT for Excel (R. Fitch Software). Normally distributed data were assessed by a one-tailed, unpaired (independent) Student's $t$ test, whereas data without normal distribution were assessed with a Mann-Whitney $U$ test $\left({ }^{*} p<0.05\right)$.

\section{Results}

APLP1 and APLP2 protein expression is upregulated during synaptogenesis

Several features of APP indicate that it belongs to the family of SAMs (Siddiqui and Craig, 2011). It has been shown previously by several groups that APP is upregulated at different developmental stages in mouse brains, which are attributed to the period of synaptogenesis (Clarris et al., 1994; De Felipe et al., 1997; Hoe et al., 2009; Vella and Cappai, 2012). Little is known so far about the synaptic features of the APP gene family members APLP1 and APLP2. Therefore, we first investigated the developmental time course of APLP1 and APLP2 expression in the cortex. Protein levels of APLP1 and APLP2 were analyzed and compared to APP in WT cortices between E14 and P65. APP levels started to increase at $\mathrm{E} 17$ with a peak at $\mathrm{P} 6$ and a gradual continuous decrease until P65 (Fig. 1A). Interestingly, APLP1 and APLP2 show the same expression pattern as APP with a peak at P6 during synaptogenesis, which was also depicted via quantification of the mature forms of APP/APLPs (Fig. 1A,C). The specificity of the antibodies used was verified using APP KO, APLP1 KO, or APLP2 KO brain lysates as negative controls (Fig. 1B). The different glycosylated forms were characterized using $N^{\prime}$ - and $O^{\prime}$-glycosidases (data not shown). Consequently, we were able to show that APLP1 and APLP2 expression is upregulated during the developmental time of synaptogenesis in a similar fashion as APP.

\section{Endogenous APP, APLP1, and APLP2 are located at the presynapse and postsynapse, tested via biochemical analysis} Having demonstrated that APLP1 and APLP2 protein levels are upregulated during synaptogenesis, we next examined whether APLP1 and APLP2 show further characteristics of SAMs, such as presynaptic and postsynaptic localization allowing trans-interaction at the synapse (Dalva et al., 2007; Baumkötter et al., 2012). For APP and APLP1, presynaptic and postsynaptic localization has previously been shown (Kim et al., 1995; Back et al., 2007; Hoe et al., 2009; Wang et al., 2009; Laßek et al., 2013). In contrast, for APLP2 only the presence at the presynapse has been documented
(Lyckman et al., 1998). Interestingly, we found that APP, APLP1, as well as APLP2 were present in optic nerve as well as sciatic nerve preparations (Fig. 1D,E). APLP1 expression in the sciatic nerve was much weaker compared to the optical nerve, possibly because APLP1 is more prominently expressed in the CNS than in the PNS. Notably, the pattern of the APLP2 full-length protein looks different in the sciatic nerve and optical nerve, mainly because of a shift in intensities toward forms with a higher molecular weight in the sciatic nerve. This could be either due to a more prominently expressed splice form of APLP2 or to different posttranslational modifications. APLP2 KO controls confirmed the specificity of the signals obtained.

To verify the localization of the APP family at presynaptic and postsynaptic sites, we analyzed synaptosomal preparations and the enrichment of the PSD fraction. Using adult WT mouse brains, we show that APP, APLP1, and APLP2 are clearly present in synaptosomal raw fractions, which contain both presynaptic and postsynaptic components, as indicated by the markers synaptophysin and PSD-95, respectively. Enrichment of the postsynaptic density was verified via strong accumulation of PSD-95 (Fig. $1 F$ ). All members of the APP gene family were also detected at low levels in the PSD fraction, although no enrichment of APP or APLPs as seen for PSD-95 was detectable. Specificity of the signals obtained was confirmed via comparison of WT and APP/APLPs KO brain samples (Fig. $1 G$ ). Together, these data show that APP, APLP1, and APLP2 are all localized predominantly to the presynaptic compartment but are also present at postsynaptic sites.

\section{Immunocytochemical analysis shows dendritic and axonal localization of endogenous APP, APLP1, and APLP2 in neurons}

The localization of endogenous APP, APLP1, and APLP2 was analyzed via immunocytochemistry in mouse primary cortical neurons at DIV7 with antibodies Y188, CT-11, and CT-12, respectively (Figs. 2, 3). The specificity of these antibodies has been tested in APP KO, APLP1 KO, or APLP2 KO mice, respectively. The presence of APP/APLPs in dendrites and axons was confirmed via costainings with the dendritic marker MAP2 (Fig. 2) or the axonal marker Taul (Fig. 3). All APP family members showed a punctate pattern in MAP2-positive dendrites and Tau1-positive axons (see arrows in Figs. 2, 3), which was absent in the corresponding KO controls. Notably, exogenously expressed epitope-tagged APP family members showed a localization that was highly similar to that of the endogenous proteins (Fig. 4A). These data further validate our biochemical findings that APP family members are also localized in presynaptic and postsynaptic neuronal compartments.

As a next step, we wanted to investigate the localization of APP, APLP1, and APLP2 in more detail in the postsynaptic compartment in dendritic spines. Whether APP family proteins are also found endogenously in postsynaptic spines was difficult to discern due to the quality of available antibodies and/or the low level of endogenous proteins at these sites. Therefore, we cotransfected HA-tagged APP family members in combination with GFP in primary hippocampal neurons at DIV17. GFP fluorescence allowed the visualization of dendritic spines. Staining with anti-HA antibody revealed only partial localization of APP and APLP2 in the head, neck, or at the bottom of dendritic spines (Fig. $4 B$, top, bottom, arrows). In contrast, APLP1 showed a very prominent localization throughout dendritic spine structures (Fig. 4B, middle). These data are consistent with the view that APLPs, and in particular APLP1, could form trans-synaptic dimers such as other SAMs. 

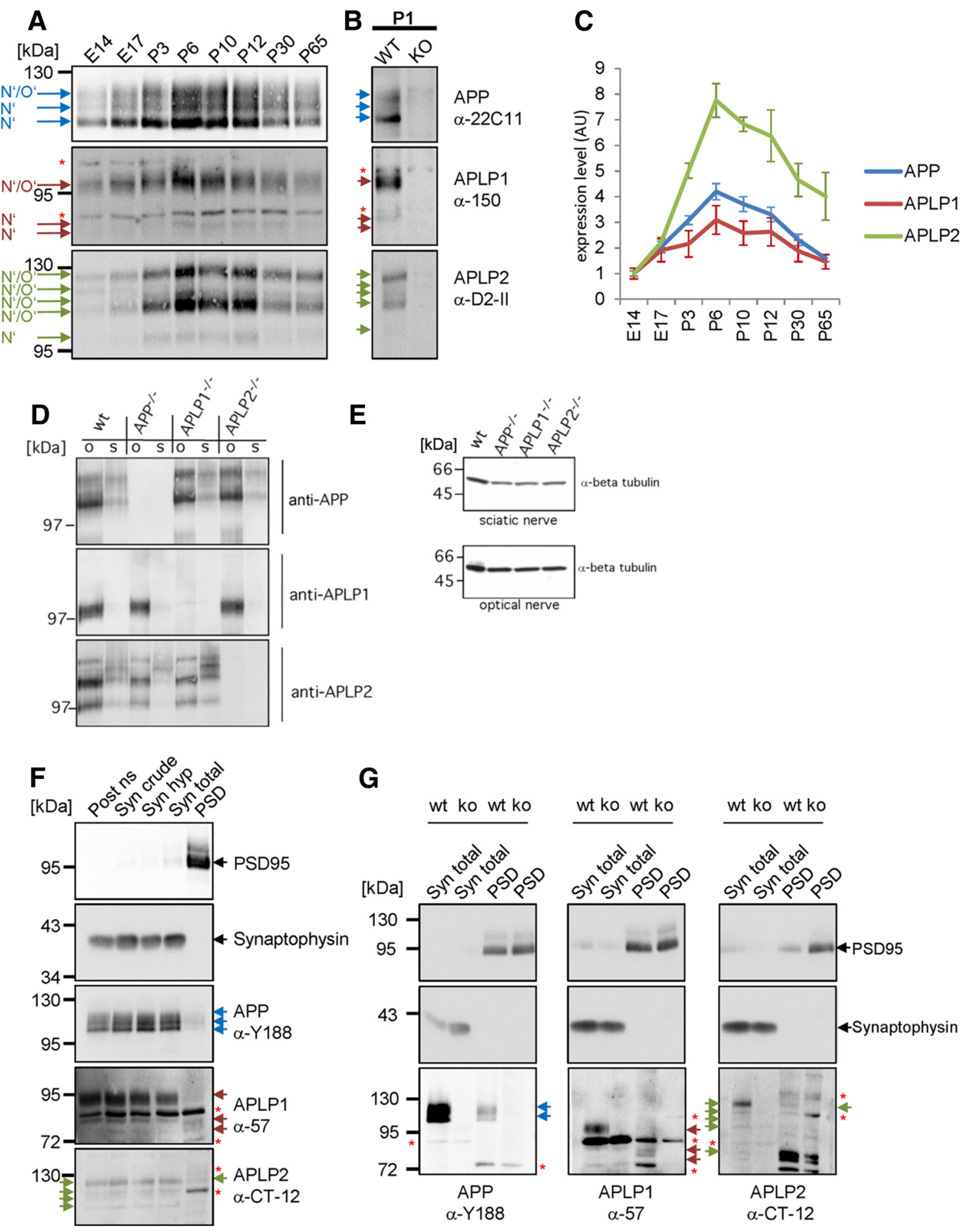

Figure 1. Expression analysis of APP, APLP1, and APLP2 protein levels in mouse cortices during development, optical, and sciatic nerve preparations and synaptosomal preparations. $A$, Mouse cortices of developmental stages E14, E17, P3, P6, P10, P12, P30, and P65 were lysed, and equal amounts of protein were separated by SDS gel electrophoresis and analyzed by Western blotting using anti-APP (22C11), anti-APLP1 (57), and anti-APLP2 (D2-II) antibodies. $N^{\prime}$ and $O^{\prime}$ refer to $N^{\prime}$ - and $O^{\prime}$-glycosylated forms, respectively. Full-length protein forms of APP, APLP1, and APLP2 are marked with blue, brown, and green arrows, respectively. Unspecific bands were marked with a red star. $B$, Specificity of the signals obtained was confirmed by comparison of lysates from WT and KO mouse cortices (P1). Unspecific signals are indicated by red stars. C, Quantification of relative APP, APLP1, and APLP2 levels at different developmental stages (E14-P65; $n=3$, bars represent mean values \pm SEM). For densitometric analysis, ImageJ was used. The signals of the mature forms were related to the overall protein amount, determined by Larva-purple staining of the PVDF membrane (data not shown). D, Optical and sciatic nerve preparations of adult APP K0, APLP1 K0, and APLP2 K0 mice compared to adult WT mice. Equal amounts of protein were loaded, and the APP gene family members were detected with primary antibodies (T-10 (anti-APP), CT-11 (anti-APLP1), and CT-12 (anti-APLP2). E, $\beta$-Tubulin staining served as a loading control. $\boldsymbol{F}$, WT mouse (C57BL/6) brain homogenates were subfractionated by differential centrifugation and analyzed by Western blot with the same primary anti-APP, anti-APLP1, and anti-APLP2 antibodies, as mentioned above. Anti-synaptophysin and anti-PSD-95 antibodies, respectively, were used as presynaptic and postsynaptic markers. Syn crude, Synaptic raw fraction. G, To confirm the specificity of the signals, Syn total and the PSD fraction were prepared from APP, APLP1, and APLP2 K0 mouse brains and corresponding littermate controls and were analyzed by Western blotting as explained previously. 

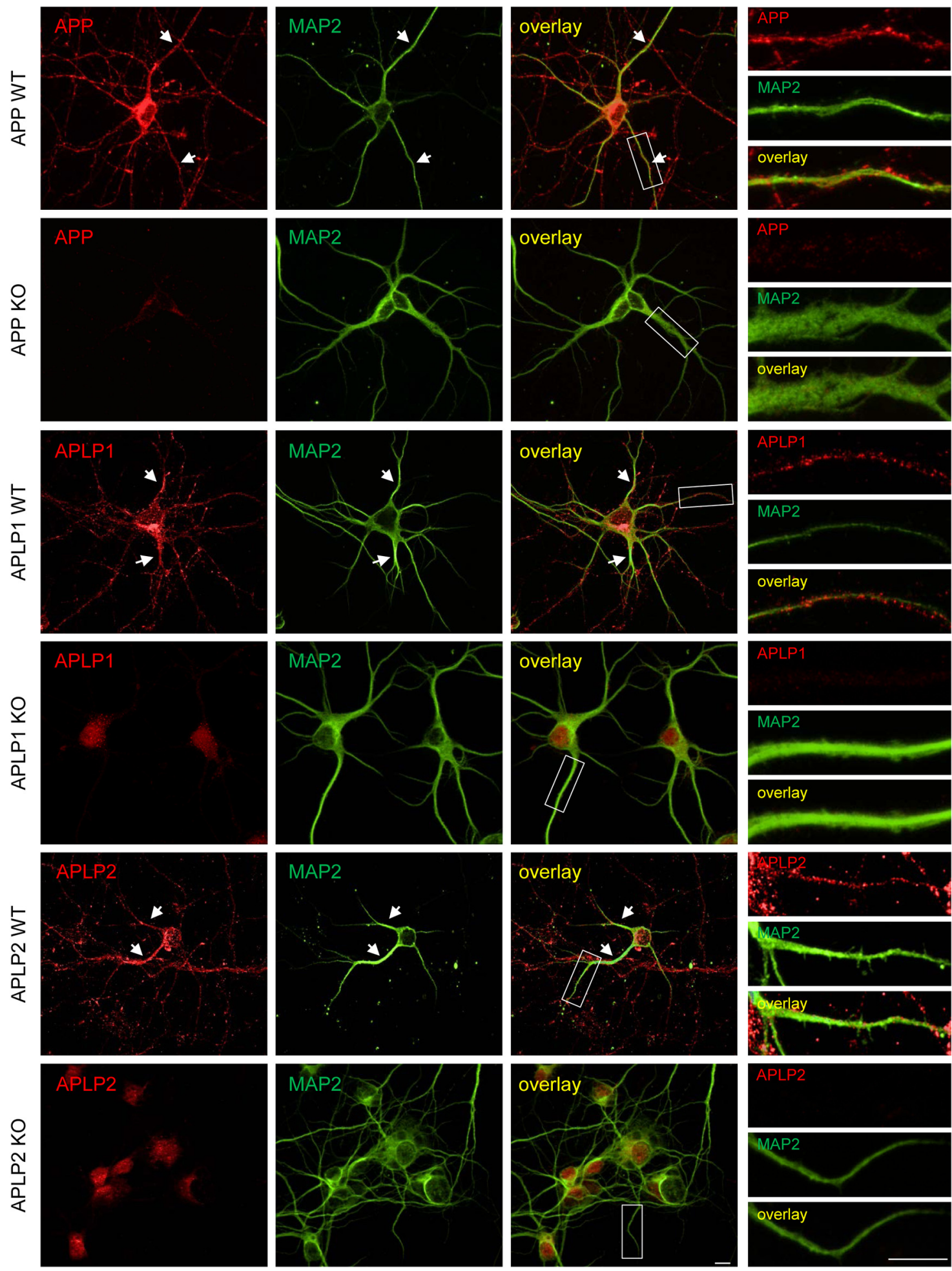

Figure 2. Analysis of the dendritic localization of APP, APLP1, and APLP2 in primary cortical neurons. Cortical WT mouse neurons (DIV7) were stained for endogenous mouse APP, APLP1, or APLP2 (red) with antibodies Y188, (T-11, or (T-12, respectively, and costained with anti-MAP2 antibody (green, dendritic marker). Colocalization of APP, APLP1, or APLP2 with the dendritic marker is indicated in yellow and highlighted by arrows. Immunocytochemistry of APP KO, APLP1 K0, or APLP2 K0 neurons (DIV7) with antibodies Y188, CT-11, or CT-12, respectively, costained with anti-MAP2 served as a negative control. Boxed areas are shown at higher magnifications. Scale bar, $10 \mu \mathrm{m}$.

\section{All APP family members have the capacity to induce} presynaptic differentiation

APP has been shown previously to induce presynaptic differentiation in coculture assays (Wang et al., 2009; Siddiqui and Craig, 2011; Baumkötter et al., 2014; Stahl et al., 2014). Since all APP family members are located at the presynapse and postsynapse, we were interested to investigate the synaptogenic properties of APLP1 and APLP2 compared to APP. Therefore, we performed a coculture assay with APP HA-, APLP1 HA-, or APLP2 HAexpressing HEK cells. GFP- or Neuroligin1 HA-expressing cells served as a negative and a positive control, respectively. Western blot analysis revealed comparable expression levels of the HA- 

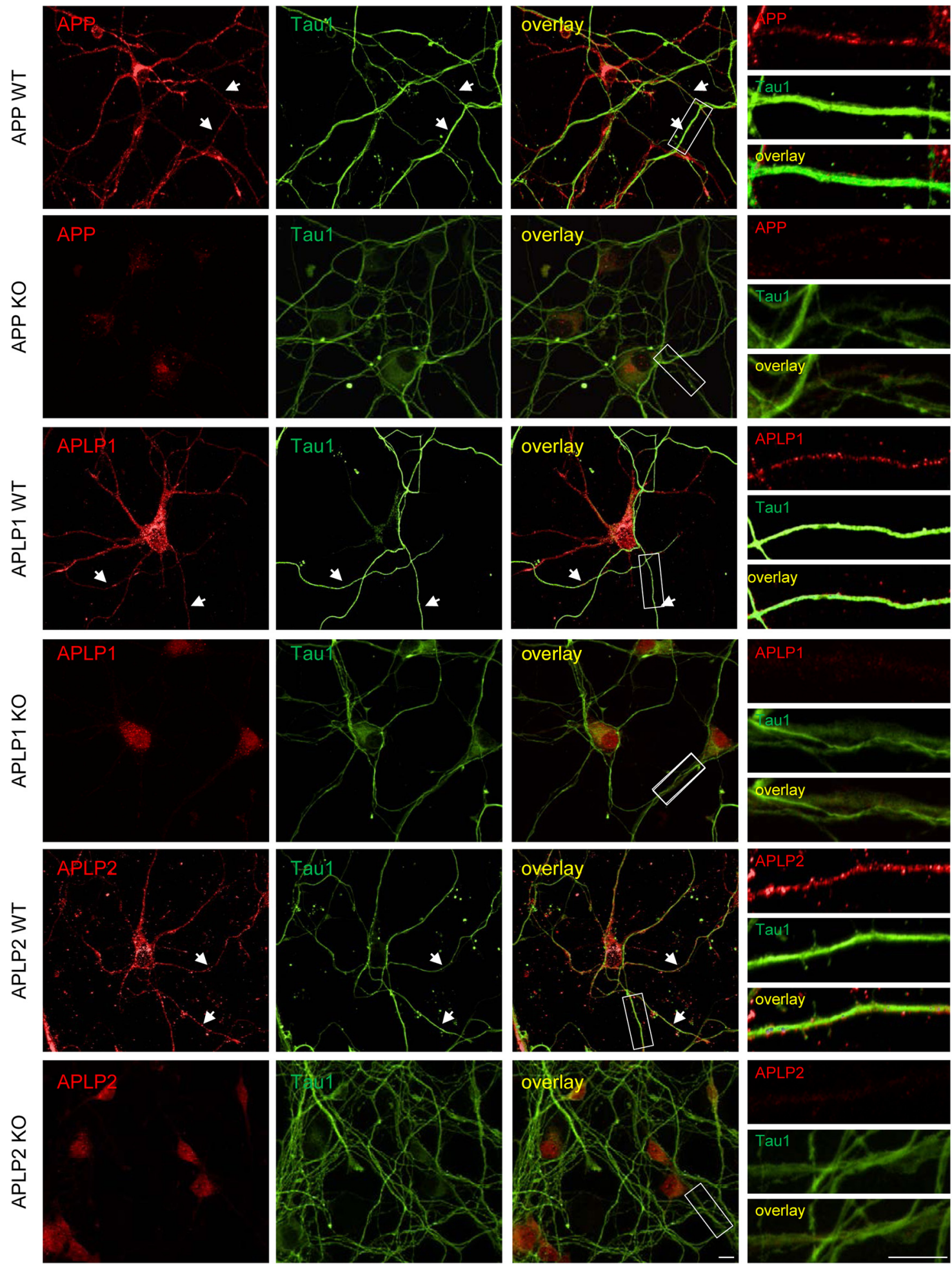

Figure 3. Analysis of axonal localization of APP, APLP1, and APLP2 in primary cortical neurons. Cortical WT mouse neurons (DIV7) were stained for endogenous mouse APP, APLP1, or APLP2 (red) with antibodies Y188, CT-11, or CT-12, respectively, and costained with anti-Tau1 antibody (green, axonal marker). Colocalization of APP, APLP1, or APLP2 with the axonal marker is indicated in yellow and highlighted by arrows. Immunocytochemistry of APP K0, APLP1 K0, or APLP2 K0 neurons (DIV7) with antibodies Y188, CT-11, or CT-12, respectively, and costained with anti-Tau1 served as a negative control. Boxed areas are shown at higher magnifications. Scale bar, $10 \mu \mathrm{m}$.

tagged proteins (Fig. 5A). The transfected HEK cells were seeded on primary cortical neuronal cultures at DIV7 and fixed $24 \mathrm{~h}$ later. The formation of presynaptic specializations can be visualized via synaptophysin staining in axons, which contact the transfected HEK cells forming so-called hemi-synapses (Scheiffele et al., 2000; Wang et al., 2009; Baumkötter et al., 2014;
Stahl et al., 2014). Staining of the dendritic marker MAP2 was used to exclude the analysis of false-positive bona fide synapses between axons and dendrites (Fig. 5B). Triple stainings, using Taul as an axonal marker, anti-HA antibody for the detection of APLP1, and anti-synaptohysin antibodies further validate synaptophysin accumulation at axons contacting HEK cells expressing 
A
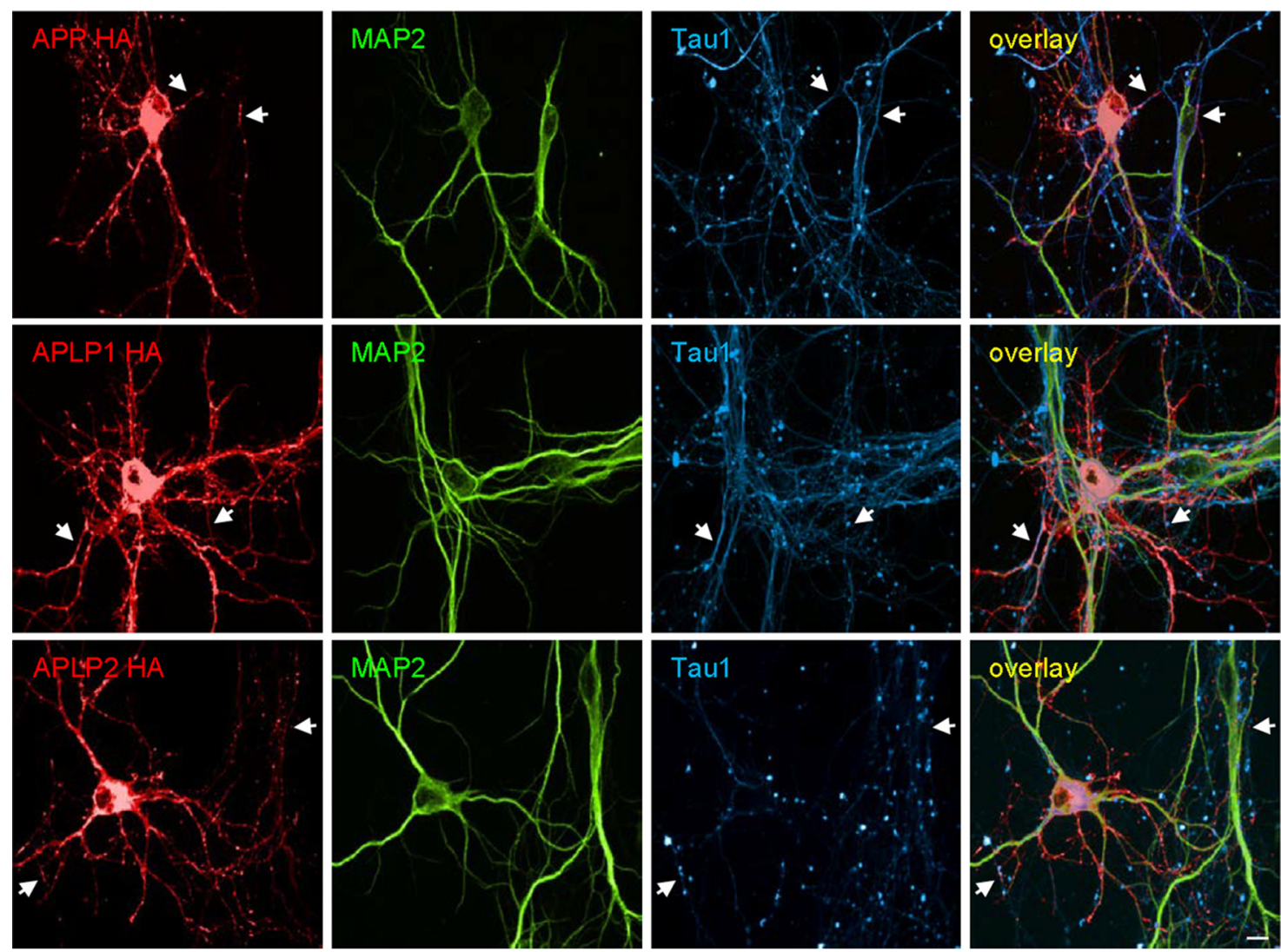

B
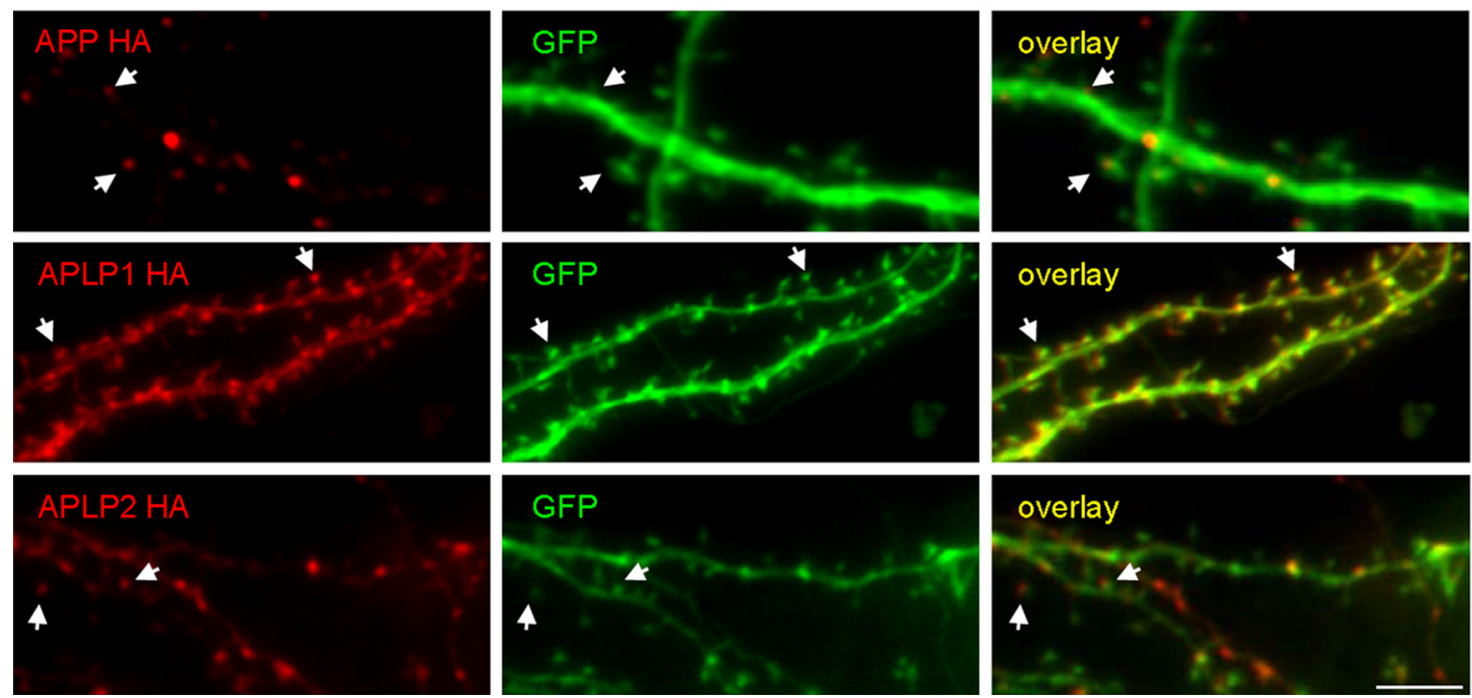

Figure 4. Analysis of axonal and dendritic localization of heterologously expressed APP, APLP1, and APLP2 in primary hippocampal neurons. A, Hippocampal mouse neurons (DIV7) expressing C-terminally HA-tagged APP, APLP1, or APLP2 were stained with anti-HA, anti-MAP2 (dendritic marker), and anti-Tau1 (axonal marker) antibodies. Arrows indicate APP, APLP1, or APLP2 localization to axons. Scale bar, $10 \mu \mathrm{m}$. B , Hippocampal mouse neurons (DIV17) expressing GFP and C-terminally HA-tagged APP, APLP1, or APLP2. After fixation, the neurons were stained with anti-HA antibody to reveal localization of the APP gene family members in dendritic spines, which were visualized by GFP. Arrows indicate APP, APLP1, or APLP2 localization to spines. Scale bar, $10 \mu \mathrm{m}$.

APLP1 (Fig. 5C). Importantly, all APP family members induced presynaptic differentiation that was significantly stronger than that of GFP-transfected cells. Quantification of synaptophysinpositive puncta per HEK cell revealed a trend for APLP1 promoting presynaptic differentiation more efficiently than APP or APLP2. However, the values did not reach statistical significance (Fig. 5D). Synaptic puncta are defined as clusters of synaptic proteins, in this case synaptophysin (Dalva et al., 2007). APLP2 showed the weakest presynapse-inducing capacity of the three APP gene family members. Neuroligin 1 , which is a well described SAM (Scheiffele et al., 2000), had a 25\% higher activity on presynapse differentiation than APLP1, which was statistically significant (Fig. 5E,G). Quantification of the area occupied by synaptophysin puncta revealed a significantly higher value for 
A

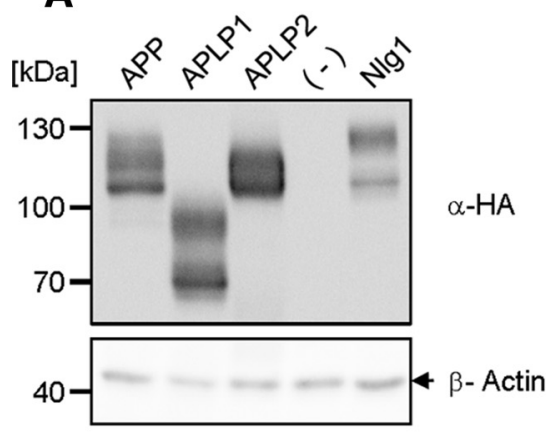

C

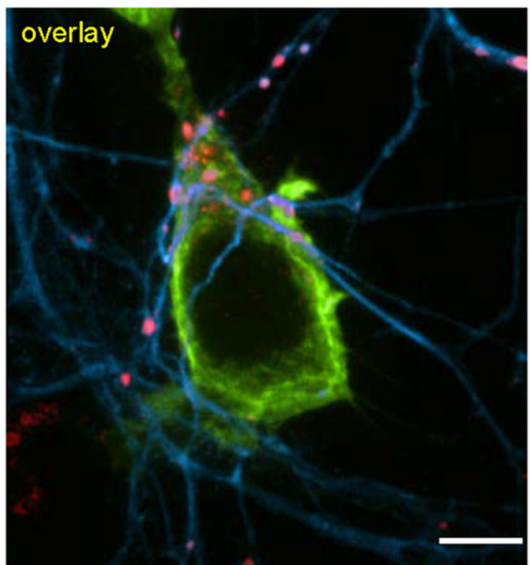

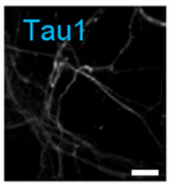
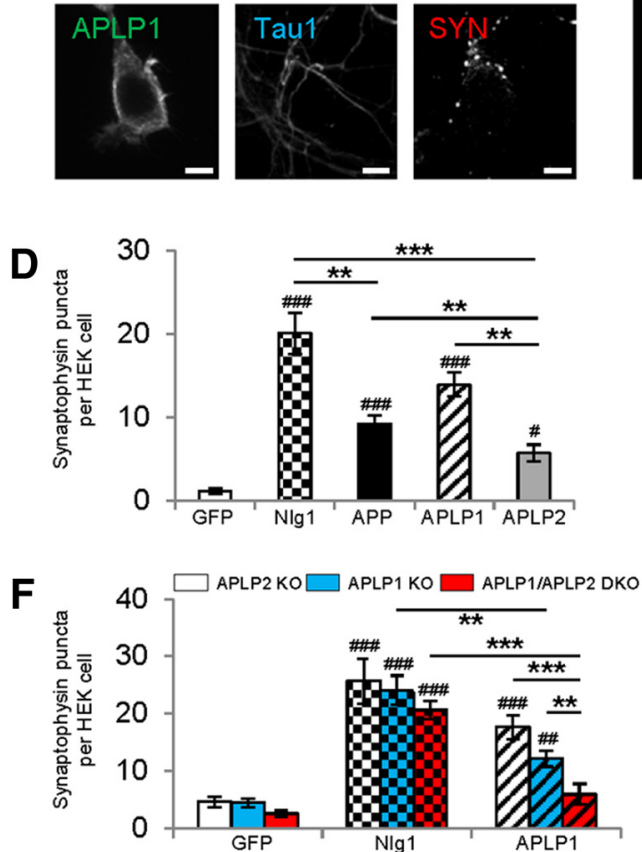

B
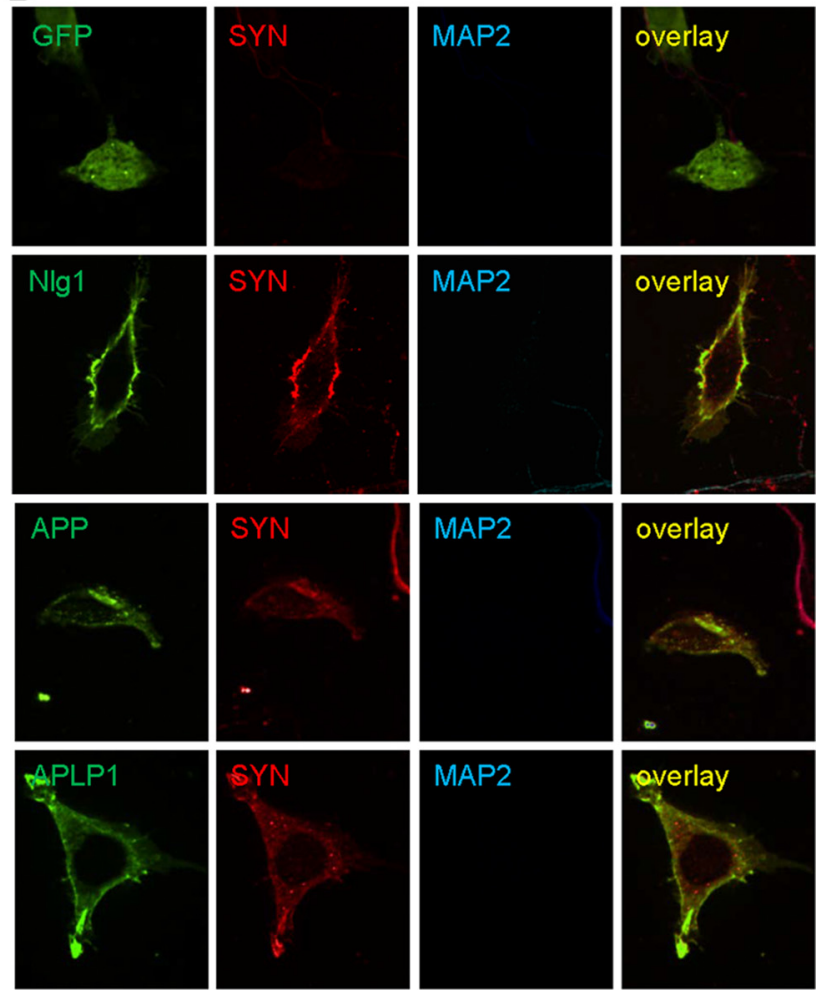

MAP2
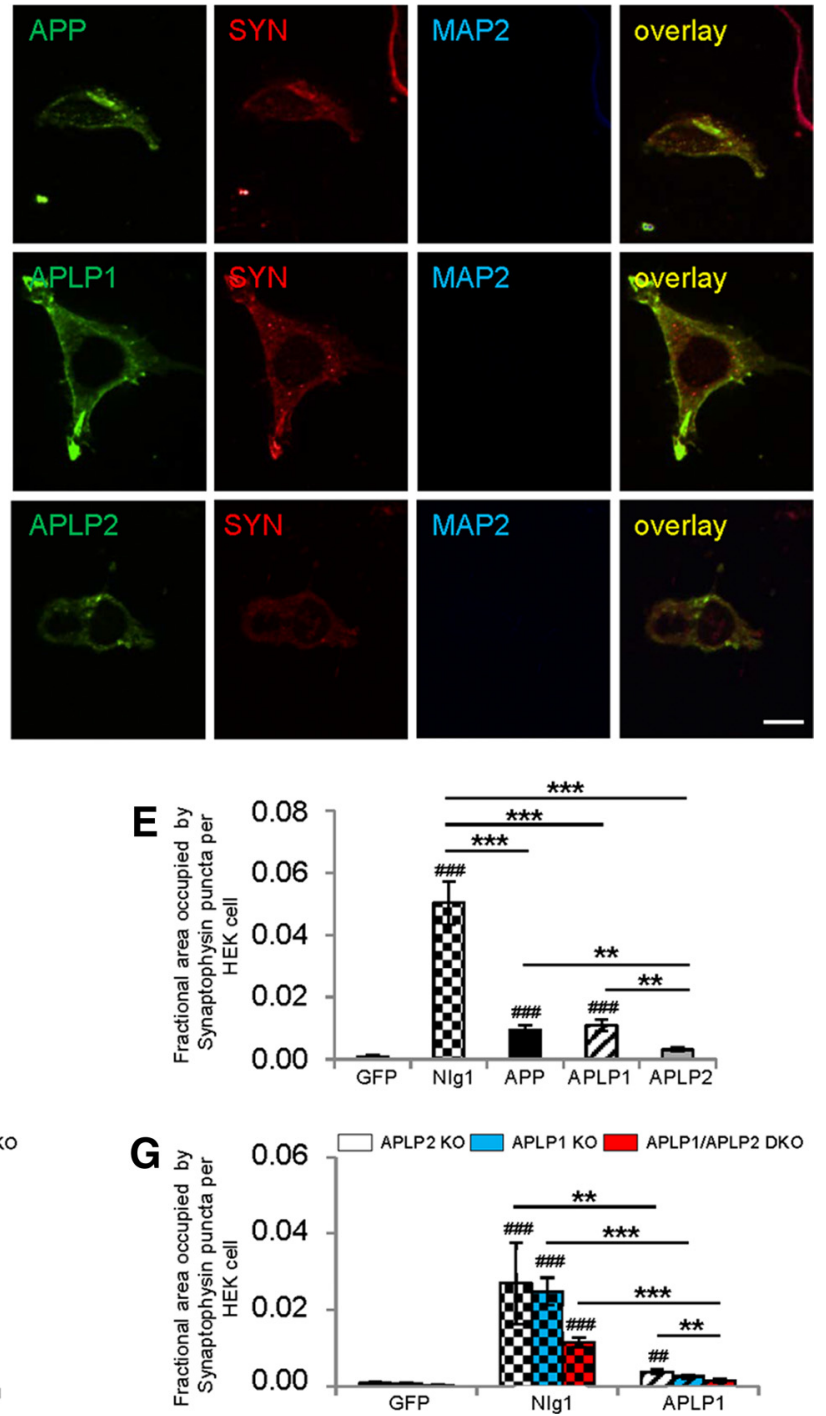

Figure 5. All APP family members show modulatory activity on presynaptic differentiation. A, Equal protein amounts of cell lysates of HEK293T cells expressing HA-tagged APP, APLP1, APLP2, or Neuroligin1 were analyzed by Western blot using anti-HA and anti- $\beta$-actin antibodies. Nontransfected cells served as the control. B, C, HEK293T cells expressing HA-tagged APP, APLP1, APLP2, Neuroligin1, or GFP were seeded on WT primary cortical neurons (DIV7) and analyzed $24 \mathrm{~h}$ later via immunocytochemistry using anti-HA, anti-MAP2 (dendritic marker), and anti-synaptophysin (marker for presynaptic vesicles) antibodies ( $\boldsymbol{B}$ ) or anti-HA, anti-synaptophysin, and anti-Tau1 (axonal marker) antibodies ( $\boldsymbol{C}$. Scale bar, $10 \mu \mathrm{m}$. $\boldsymbol{D}$, Quantification of synaptophysin-positive puncta per HEK293T cell. E, Quantification of synaptophysin-covered area per HEK293T cell. Bars represent mean \pm SEM values of at least four independent experiments $(n>19 / N \geq 4$; Kruskal-Wallis test followed by Dunn's multiple-comparison test; the\# symbol above each bar is in comparison with GFP. The asterisks on top of the lines are comparison between the specific pair. ${ }^{*} p<0.05{ }^{* *} p<$ 0.01 , and ${ }^{* * *} p<0.005 . F, G$, Coculture assay using HEK293T cells transfected with GFP, APLP1, or Neuroligin 1 seeded on APLP1 K0 or APLP1/APLP2 DKO neurons. For control, we used either WT littermate controls (data not shown) or APLP2 K0 littermate control neurons. Notably, APLP1 and Neuroligin1 synaptogenic activity in APLP2 K0 neurons was undistinguishable from that observed for WT neurons. The\# symbol above each bar is in comparison with GFP. The asterisks on top of the lines are comparison between the specific pair. $F$, Quantification of synaptophysin-positive puncta per HEK293T cell $(n>24 / N=3)$. (G) Quantification of synaptophysin-covered area per HEK293T cell $(n>24 / N=3)$. Bars represent the mean \pm SEM; Kruskal-Wallis test followed by Dunn's multiple comparison test; the asterisks on top of the lines are comparison between the specific pair. ${ }^{*} p<0.05,{ }^{* *} p<0.01$, and ${ }^{* * *} p<0.005$ ). 
Neuroligin 1 compared to the APP family members, where only APLP1 reached statistical significance in comparison to the GFP control (Fig. 5E). This indicates that Neuroligin1 and APLP1 induce larger synaptophysin puncta than APP or APLP2. Together, these data suggest that all members of the APP family show synaptogenic activity.

Moreover, to test whether presynaptic APLP1 is required for the synaptogenic activity of APLP1 expressed in HEK293T cells, we performed the above-described coculture assay with APLP1 KO neurons instead of WT neurons. We observed only a slight nonsignificant change in the number of synaptophysin puncta and the fractional area of synaptophysin puncta per HEK cell by comparison of APLP1-expressing HEK cells contacted by APLP1 KO versus wild-type littermate control neurons [Fig. $5 F, G ; n>$ 9/N $\geq 4$; puncta: $p=0.202(p>0.05)$; area: $p=0.209(p>$ $0.05)]$. As APP/APLPs can form heterotypic trans-cellular dimers (Soba et al., 2005), we assumed that the presynaptic loss of APLP1 might be compensated by APLP2 similar as observed before for synaptogenic activity of APP that was only impaired in APP/ APLP2 DKO neurons but not in APLP2 KO neurons (Wang et al., 2009). Therefore, we analyzed in the next step APLP1 synaptogenic activity using APLP1/APLP2 DKO neurons. GFP, APLP1, and Neuroligin 1 synaptogenic activity in APLP2 KO neurons was undistinguishable from that observed for WT neurons $(p=$ $0.340, p=0.305, p=0.196$, respectively; data not shown) that were cultured as internal littermate controls together with APLP1 KO neurons. However, by comparing APLP1/APLP2 DKO neurons with APLP2 single-KO neurons (littermate controls), the ability of APLP1 to induce presynaptic synaptophysin accumulation at contacting axons was significantly reduced in respect to the number of synaptohysin puncta as well as to the size of the synaptophysin-covered area (Fig. 5F,G). Consistently, GFP expression caused no significant increase of synaptophysin accumulation at axonal contact sites. In contrast, Neuroligin 1 synaptogenic activity was unaffected in APLP1/APLP2 DKO neurons. Together, these data strongly suggest that APLP1 synaptogenic activity depends on trans-cellular interaction with APLP1 and/or APLP2.

\section{APLP1 shows stronger trans-dimerization properties and a more prominent cell surface localization than APP and APLP2}

Since our results indicate that APLP1 has a prominent presynapseinducing capacity, we wanted to get insights into the underlying mechanism. First, we examined whether there are also differences in cell adhesion properties of APP/APLPs. This was addressed using an $\mathrm{F}_{\mathrm{C}}$ bead aggregation assay. An $\mathrm{F}_{\mathrm{C}}$ tag had been appended C-terminally to the extracellular domains of APP and APLPs (Caillé et al., 2004; Klevanski et al., 2014). Purified APPex- $\mathrm{F}_{\mathrm{C}}$, APLP1ex- $F_{C}$, and APLP2ex- $F_{C}$ were coupled to protein A polystyrene beads, and trans-dimer formation was analyzed by a standard bead aggregation assay. Quantification of this assay revealed that APLP1 and APLP2 both show significantly higher transinteraction properties compared to APP (Fig. 6A). Microscopic analysis of the bead clusters confirmed stronger clustering of APLP1 and APLP2 compared to APP (Fig. 6B). No significant differences regarding clustering were observed between APLP1 and APLP2 $(p<0.141$; Fig. 6A).

Next, we addressed the question if stronger cell surface localization of APLP1 might contribute to its more prominent transsynaptic signaling capacity. Indeed, cell surface biotinylation of transiently transfected HEK cells showed that APLP1 is more prominently localized at the cell surface compared to APP and APLP2, looking at the ratio of streptavidin IP samples versus input controls (Fig. $6 \mathrm{C}$ ). Together, these experiments demonstrate that APLP1 shows the highest levels of cell surface localization and the strongest trans-dimerization properties of the APP family members.

\section{APP gene family members are proteolytically processed to a different extent}

Next we aimed to investigate whether proteolytic conversion might contribute to the regulation of different cell surface levels of the APP family members. For this purpose, C-terminally HA-tagged APP, APLP1, and APLP2 were transiently transfected in HEK cells and analyzed by Western blotting $24 \mathrm{~h}$ posttransfection. Direct loads of equal protein amounts of cell lysates were analyzed, using $\beta$-actin levels as the loading control. Fulllength APP/APLPs as well as their corresponding C-terminal fragments were visualized via anti-HA antibody (Fig. 6D). Quantification of CTFs versus full-length protein revealed that CTF levels of APLP1 are reduced compared to the other APP family members (Fig. $6 E$ ). As a next step, we wanted to analyze whether this result also holds true for secreted forms of the APP gene family members. HEK cells were transfected with $\mathrm{N}$-terminally myc-tagged APP, APLP1, and APLP2 constructs. The following day, media were conditioned for $2 \mathrm{~h}$ to avoid steady-state levels of the shedded forms. Direct loads of cell lysates and media (equal amounts of proteins) were analyzed via Western blot detection with anti-myc antibody (Fig. 6F). Quantification of the shedded forms versus the corresponding full-length protein surprisingly revealed that APLP1-secreted forms are not reduced compared to those of APP and APLP2 (Fig. $6 G$ ). To test, whether shedding of the APP family members at endogenous levels is comparable in primary neuronal cultures, mouse cortical neurons were analyzed at DIV8, the time point when the coculture assay had been performed. Western blot detection indicated that APLP1 is shedded to a higher extent than APP or APLP2 also in primary cortical neuronal cultures (Fig. 6H). Together, the extent of APLP1 processing is different compared to that of APP and APLP2, showing lower levels of CTFs but higher amounts of secreted forms. These data suggest that differences in proteolytic conversion cannot explain the increased cell surface levels of APLP1.

\section{APLP1 has a slower endocytosis rate than APP or APLP2}

All APP family members contain the endocytosis motif NPTY in their $\mathrm{C}$ terminus and are known to be internalized. We therefore analyzed as a next step the endocytosis rate of the APP family members using $\mathrm{N}$-terminally myc-tagged APP, APLP1, or APLP2 fusion proteins, exogenously expressed in N2a cells. Myc APP $\Delta$ CT lacking the endocytosis motif YENPTY (Koo and Squazzo, 1994) served as a negative control. The cells were incubated with an $\alpha$-myc (9E10) antibody at $4^{\circ} \mathrm{C}$ to label APP/APLPs at the surface. Afterwards, endocytosis was allowed at $37^{\circ} \mathrm{C}$ for $0,5,10$, or 20 min. Remaining surface APP/APLPs and internalized APP/ APLPs were labeled with the secondary antibody, Alexa Fluor 594 (Fig. $7 A$, red). For quantification, the signal intensity of endocytosed APP (internal cell) was compared to the total intensity of the cell (whole cell including the plasma membrane; Fig. $7 B$ ). Interestingly, after $20 \mathrm{~min}$, endocytosis of APLP1 was significantly impaired compared to the other APP family members. The endocytosis-deficient APP $\Delta \mathrm{CT}$ showed the strongest reduction regarding internalization from the plasma membrane of the proteins analyzed. There was no significant difference in the endocytosis rate between APP and APLP2 after $20 \mathrm{~min}$. Together, we demonstrate that APLP1 is significantly less internalized compared to APP and APLP2. 
A

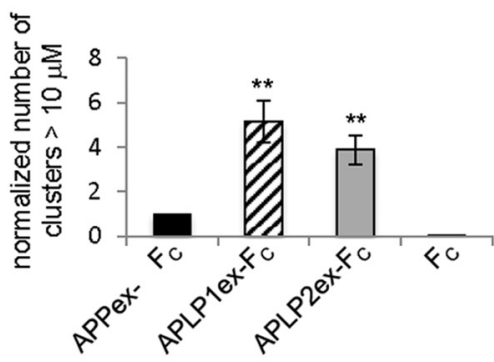

C

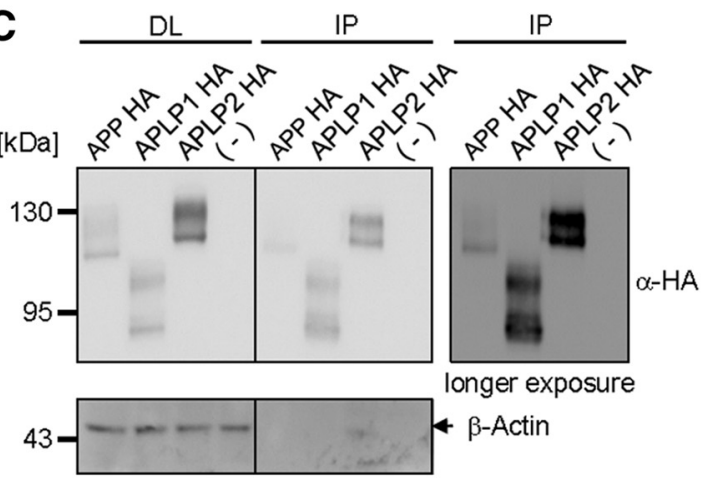

B

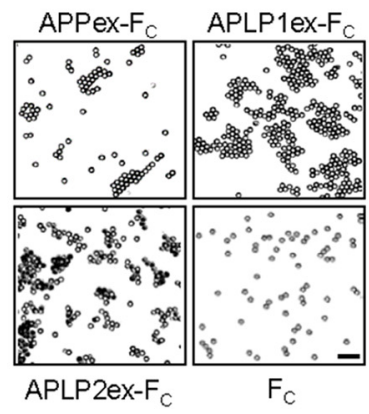

D

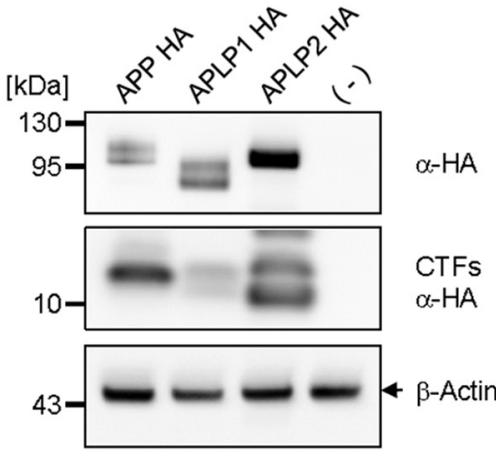

E

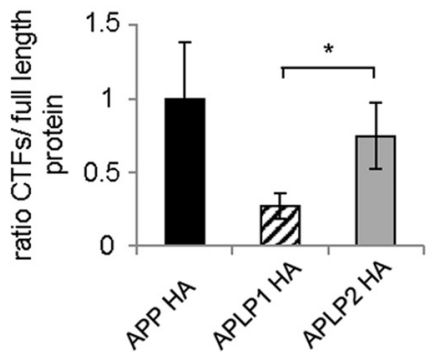

G

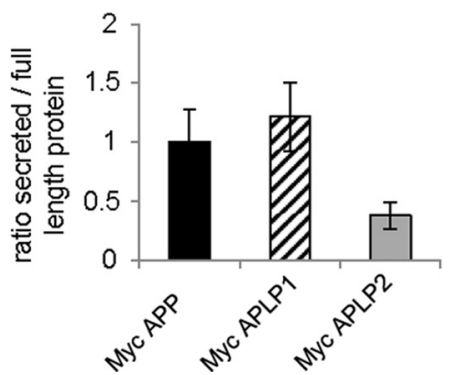

$\mathbf{F}$

Myc APP Myc APLP1 Myc APLP2

[kDa] Lys Med Lys Med Lys Med

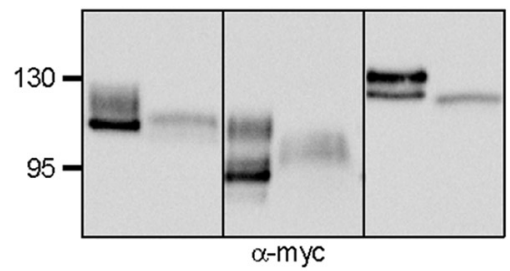

H

APP

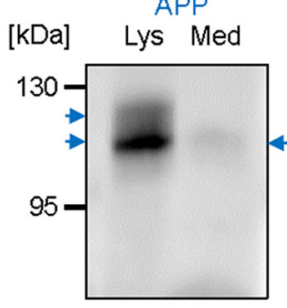

$\alpha-22 \mathrm{C} 11$

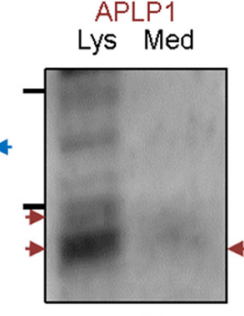

$\alpha-150$

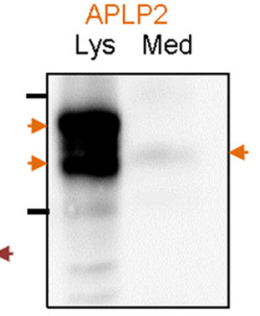

$\alpha-\mathrm{D} 2-\mathrm{II}$

Figure 6. Cell adhesion properties, cell surface levels, and proteolytic processing of APP, APLP1, and APLP2. A, Quantification of clustered beads coated with either $F_{C}$ APPex- $F_{C}, A P L P 1 e x-F_{C}$, or APLP2ex- $F_{C}$. Clusters $>10 \mu$ m were measured with a Beckman Coulter Z2 Counter. Bars represent mean \pm SEM values of at least three independent experiments normalized to APPex- $F_{C}(n \geq 3$; Student's $t$ test, ${ }^{* *} p<0.01$ compared to APP). $B$, Affinity-purified fusion proteins of the extracellular domains of APP (APPex) or APLP2 (APLP2ex) and the $F_{C}$ domain of human IgG1 ( $F_{C}$ ) heterologously expressed in COS-7 cells were coated on protein A beads and subjected to a standard bead aggregation assay. Representative bright-field images of clustered protein $A$ polystyrene beads coated with APPex- $F_{C}$ (top left), APLP1- $F_{C}$ (top right), APLP2ex- $F_{C}$ (bottom left), or $F_{C}$ (bottom right). Scale bar, $10 \mu$ m. C, Cell surface biotinylation of transiently transfected APP HA, APLP1 HA, and APLP2 HA HEK293T cells. Direct load of cell lysates is shown in the left panel together with the $\beta$-actin loading control. In the right panel, APP cell surface levels after streptavidin immunoprecipitation and Western blot detection with anti-HA antibody are shown, and $\beta$-actin as a negative control for intracellular proteins at the cell surface is shown. $\mathbf{D}$, HEK cells were transiently transfected with C-terminally HA-tagged APP, APLP1 and APLP2 constructs. Cell lysates were analyzed with anti-HA antibodies to detect full-length APP, APLP1 and APLP2 and their corresponding CTFs via Western blot. $\beta$-Actin served as a loading control. $\boldsymbol{E}$, Quantification of data shown in $\boldsymbol{D}$. Kruskal-Wallis test followed by Dunn's multiple-comparison test and Bonferroni's correction $\left(n=4 ;{ }^{*} p<0.05 ;{ }^{* *} p<0.001 ;{ }^{* *} p<0.0001\right.$; bars represent the mean \pm SEM). $\boldsymbol{F}$, N-terminally myc-tagged APP, APLP1, and APLP2 constructs were transiently transfected in HEK293T cells. Cell lysates were analyzed with antibody myc to detect full-length APP, APLP1, and APLP2 as well as their secreted forms via Western blot. $\beta$-actin served as a loading control. Lys and Med indicate lysate and media samples, respectively. G, Quantification of data shown in $\boldsymbol{F}$. Kruskal-Wallis test followed by Dunn's multiple-comparison test and Bonferroni's correction ( $n=7$; ${ }^{*} p<$ $0.05 ; * * 0.001 ; * * * 0.0001$; bars represent the mean $\pm \mathrm{SEM})$. $\boldsymbol{H}$, Shedding of endogenous levels of APP family members was analyzed in primary mouse cortical cultures at DIV8. Media were conditioned for $6 \mathrm{~h}$, and equal volumes of cell lysates and media were analyzed. APP full-length protein and sAPP were detected with antibody 22C11, APLP1 full-length protein and sAPLP1 were detected with antibody 150 and APLP2 full-length protein and SAPLP2 were detected with antibody D2-II. 
The APP family members bind to the X11 family members

As we could demonstrate before, both APLP1 and APLP2 show higher transdimerization properties than APP (Fig. 6). This results in the question why APLP2 does not have a stronger effect in the coculture assay (Fig. 5). For the synaptic adhesion molecules Neurexin, SynCAM, Calsyntenin3, and APP, binding to X11 is thought to be a key signaling element that results in the differentiation of presynapses (Biederer et al., 2002; Araki et al., 2003; Wang et al., 2009; Muller and Zheng, 2012; Pettem et al., 2013). Despite previous evidence that APP may interact with X11 proteins, a systematic analysis of all three APP family members and their binding to all X11 proteins has not been performed so far. We addressed this question via coimmunoprecipitations. $\mathrm{N} 2 \mathrm{a}$ cells were transiently cotransfected with APP HA, APLP1 HA, or APLP2 HA and Flag-tagged $\mathrm{X} 11 \alpha, \mathrm{X} 11 \beta$, or $\mathrm{X} 11 \gamma$. Cotransfections of X11 $\alpha$, X $11 \beta$, or X $11 \gamma$ with empty vector served as negative controls. HA-tagged APP family members were pulled down with HA beads. Western blot detection with $\alpha$-Flag antibody revealed the binding of APP, APLP1, and APLP2 to all members of the X11 family (Fig. $8 A-C$ ). This outcome suggests that X11 binding of the APP family members might contribute to presynaptic signaling.

Aged APLP1 KO mice show no LTP deficits but decreased mEPSC

frequency and reduced spine density So far, our data indicate an important function for APLP1 during synaptogenesis in vitro. Therefore, we also wanted to investigate the synaptic role of APLP1 in vivo. Aged APP KO mice have previously been shown to exhibit deficits in LTP at the hippocampal CA3/CA1 pathway (Ring et al., 2007). LTP is a cellular process implicated in learning and memory (Bliss and Lomo, 1973), giving rise to synaptic plasticity (Herring and Nicoll, 2016). We therefore examined the activity-dependent synaptic plasticity of young (4-6 months old) and aged (11-13 months old) APLP1 $\mathrm{KO}$ mice versus their littermate controls. After 20 min of stable baseline recording, LTP was induced by TBS of the Schaffer collateral synapse and monitored for $60 \mathrm{~min}$ (Fig. 9A). LTP was not altered between APLP1 KO mice and littermate controls, neither in young mice (4-6 months of age; data not shown) nor in aged mice (11-13 months; Fig. 9A, B).

However, analysis of basal synaptic transmission expressed as the strength of fEPSP responses to excitatory synaptic stimulation revealed impairments for aged APLP1 KO mice. Increasing $\left.{ }^{* *} p<0.01,{ }^{* * *} p<0.001\right)$.
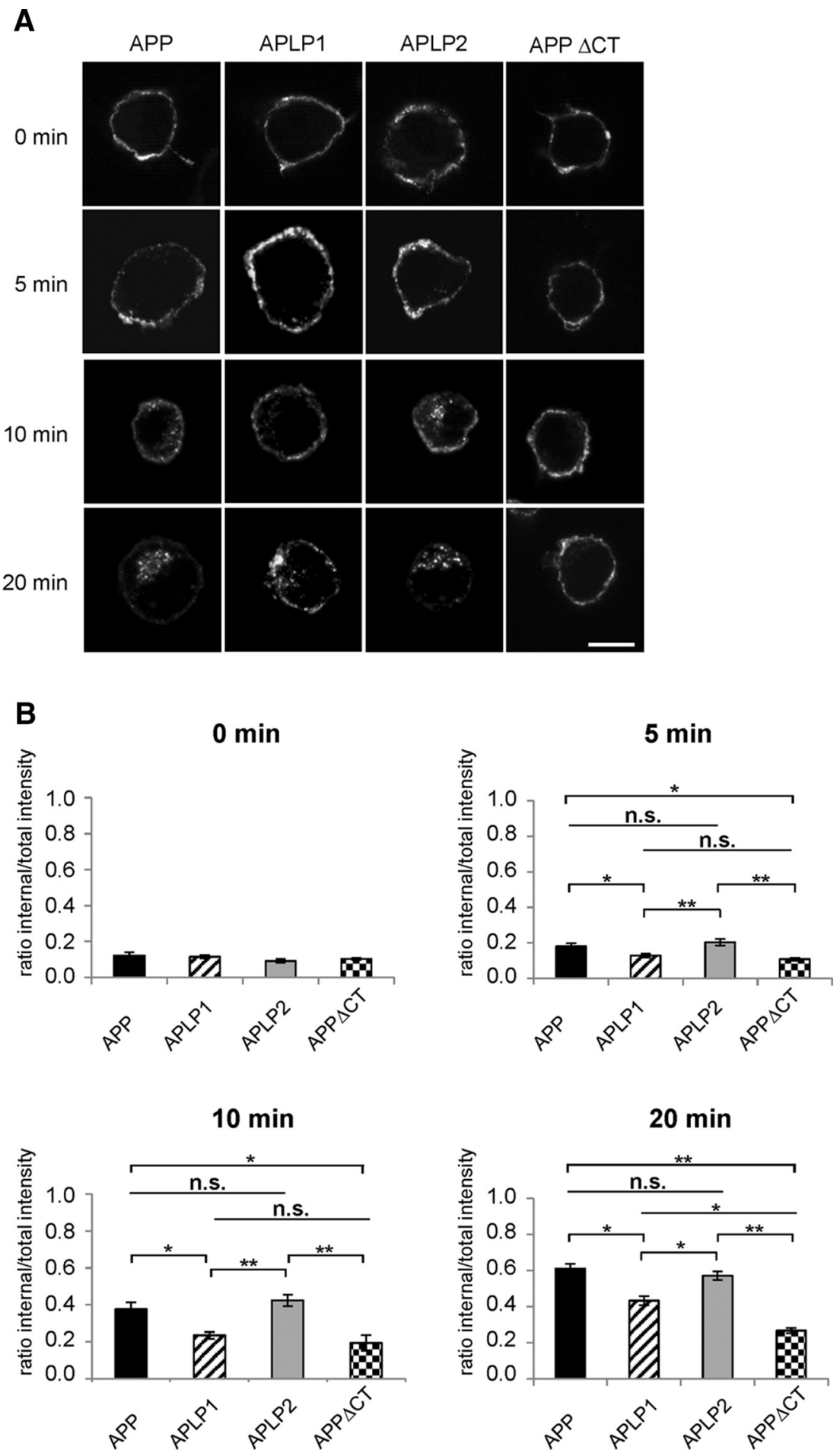

Figure 7. APLP1 shows a slower endocytosis rate than APP and APLP2. A, Immunofluorescence images of N2a cells transiently transfected with N-terminally c-myc-tagged APP, APLP1, APLP2, and APP $\triangle$ CT as a negative control. The endocytosis assay was performed at four different time points $(0,5,10$, and $20 \mathrm{~min})$. Immunolabeling was performed with the same anti-myc antibody for cell surface APP/APLPs as well as endocytosed intracellular APP/APLPs (Alexa Fluor 594). Scale bar, $10 \mu \mathrm{m}$. B, Quantification of internal/total intensity ratio for all the constructs used at different endocytosis time points. Bars represent the mean \pm SEM; $n=$ 30 (three biological replicates). Statistical analysis was performed using one-way ANOVA with Tukey's post hoc test $\left({ }^{*} p<0.05\right.$,

the fiber volley amplitude (Fig. 9D) or the stimulus intensity (Fig. 9C) resulted in significantly reduced strengthening of fEPSP responses in aged, but not in young, APLP1 KO mice (data not shown). The amplitude of the fiber volley is representative for the number of axons firing an action potential and so serves as an 
A

(a-Flag)

$(\mathrm{a}-\mathrm{HA})$
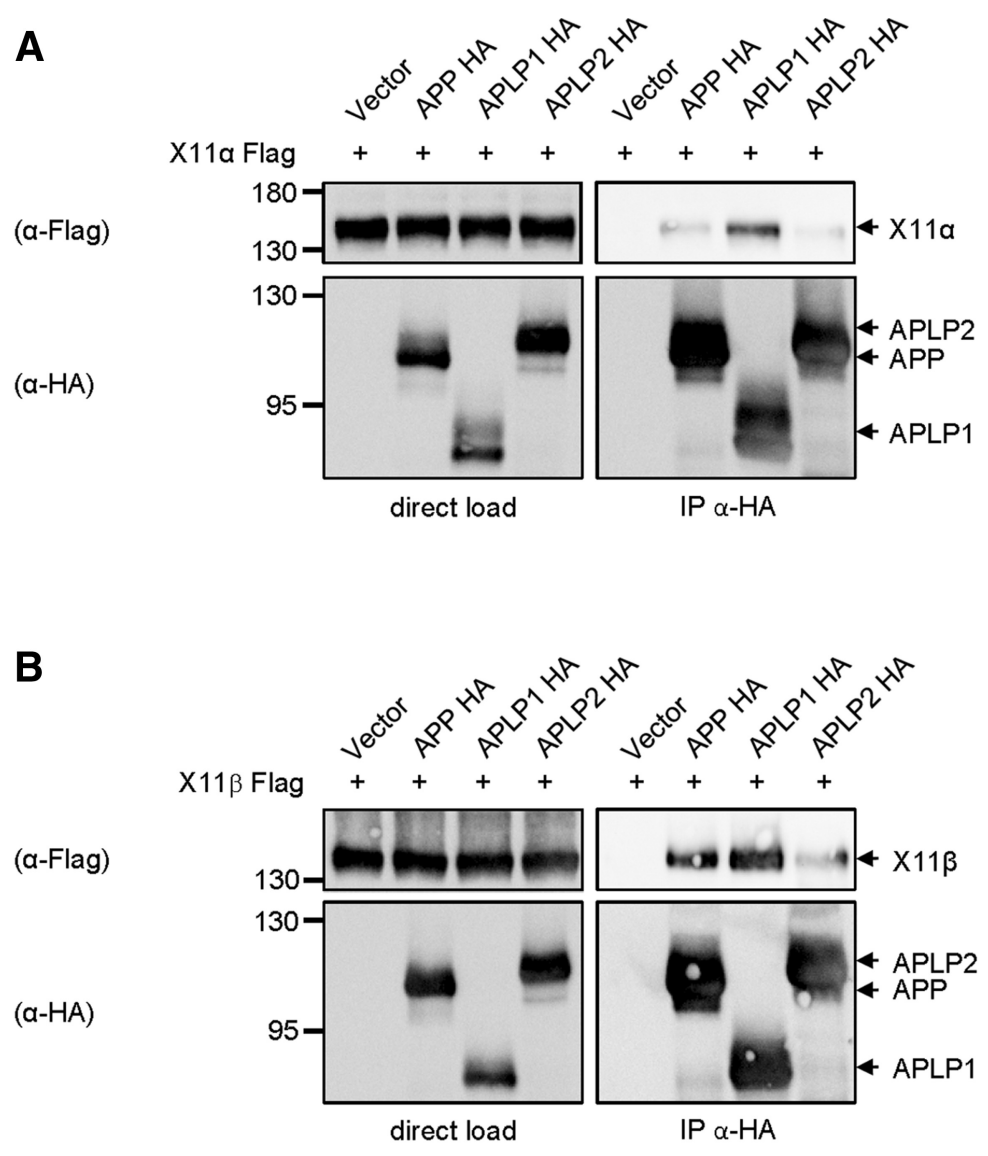

C

(a-Flag)

$(\alpha-\mathrm{HA})$

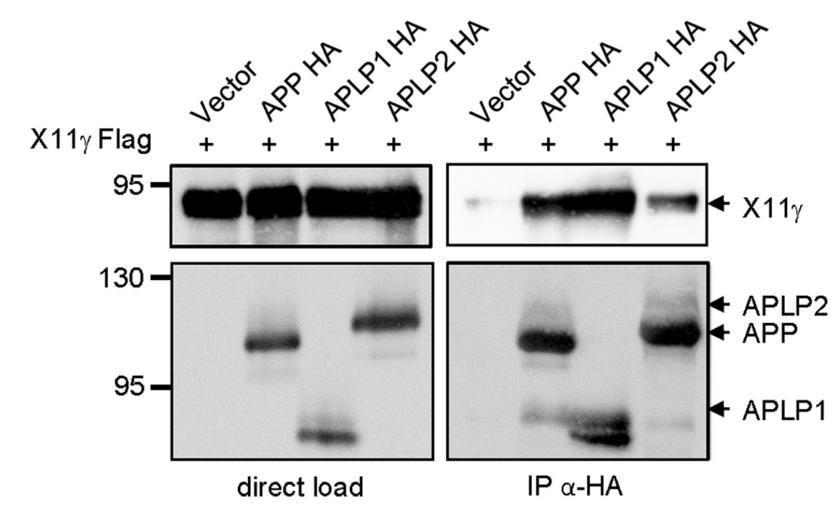

Figure 8. $\quad A-C, A P P$ gene family members bind all X11 family members. N2a cells were transiently cotransfected with C-terminally HA-tagged APP, APLP1, and APLP2 constructs and X11 $\alpha$ Flag (A) X11 $\beta$ Flag (B), and X11 $\gamma$ Flag (C). A-C, N2a cells transfected with $\mathrm{X} 11 \alpha \mathrm{Flag}(\boldsymbol{A}), \mathrm{X} 11 \beta \mathrm{Flag}(\boldsymbol{B})$, and $\mathrm{X} 11 \gamma \mathrm{Flag}(\boldsymbol{C})$, and empty vector served as a negative control. Equal amounts of cell lysates were loaded directly on an SDS gel and analyzed via Western blot with primary antibodies Flag and HA. Equal amounts of proteins were used for immunoprecipitation of HA-tagged APP family members in cell lysates with HA agarose beads. The samples were separated on an SDS gel and Western blot detection of X11 family members followed with the primary antibody $\alpha$-Flag. The same membrane was incubated afterwards with antibody HA to detect total amounts of the immunoprecipitated APP family members ( $n=3$ for each member of the X11 family).

estimate of the strength of an afferent input. As the amplitude remains the same (like the stimuli intensity applied) in controls and APLP1 KOs but evokes smaller fEPSP responses in aged APLP1 KO mice, the defect seems either to be related to postsynaptic alterations or could be due to a lower number of synapses.

To determine putative presynaptic changes in APLP1 KO mice, we analyzed PPF, a form of short-term plasticity. It de-
(a-Flag)

$(\mathrm{a}-\mathrm{HA})$

(a-Flag)

$(\mathrm{a}-\mathrm{HA})$

(a-Flag)

$(\mathrm{a}-\mathrm{HA})$

scribes the ability of synapses to increase neurotransmitter release on the second of two closely following afferent stimuli. Analyzing the ratio of the fEPSP of slope 2 to that of slope 1 revealed unchanged PPF characteristics in younger (data not shown) as well as older APLP1 KO mice and littermate controls (Fig. 9E), suggesting normal presynaptic function in APLP1 KO mice.

We also wanted to examine synaptic transmission in aged (11-13 months of age) APLP1 KO mice without artificial stimulation. Therefore, we performed wholecell patch-clamp recordings from pyramidal neurons in the hippocampal CA1 region to analyze mEPSCs in the presence of the action potential inhibitor TTX (Fig. $9 F)$. Interestingly, the mEPSC frequency was significantly decreased in APLP1 KO mice compared to littermate controls while the mEPSC amplitude and the decay time were unchanged (Fig. 9F-I). The unchanged mEPSC amplitude shows that the density and conductance of postsynaptic receptors are not affected. The reduced mEPSC frequency in aged APLP1 $\mathrm{KO}$ mice suggests a decrease in the number of functional synapses or may be a decrease in the readily releasable pool size or vesicular turnover rate.

To clarify whether the number of synapses is altered in APLP1 KO mice, we evaluated the spine density of CA1 pyramidal cells in second- or thirdorder dendritic branches of apical dendrites in midapical regions of the stratum radiatum as a correlate of excitatory synapses in young and aged APLP1 KO mice. Consistent with unaltered basal synaptic transmission in young mice (data not shown), Golgi stainings did not reveal significant changes in spine density in 14-week-old animals (Fig. 9J,L). In contrast, and highly consistent with reduced mEPSP frequency, spine density was prominently reduced in apical $(\Delta 14 \%)$ as well as basal $(\Delta 10 \%)$ dendritic segments of aged (55 weeks old) APLP1 KO mice, compared to littermate controls (Fig. $9 K, M$ ). Based on our analysis of spine density, we expected a reduction in synaptic density of $\sim 14 \%$ that we did not observe in quantitative analyses of binary images from synatophysin staining (data not shown). This is most likely due to the intraexperimental variability of immunohistological stainings, which likely is caused by differences in the fixation of the tissue.

Together, our data demonstrate that aged APLP1 KO mice show significantly decreased spine numbers, affecting basal transmission and mEPSC frequency, whereas synaptic plasticity appeared to be unchanged. 

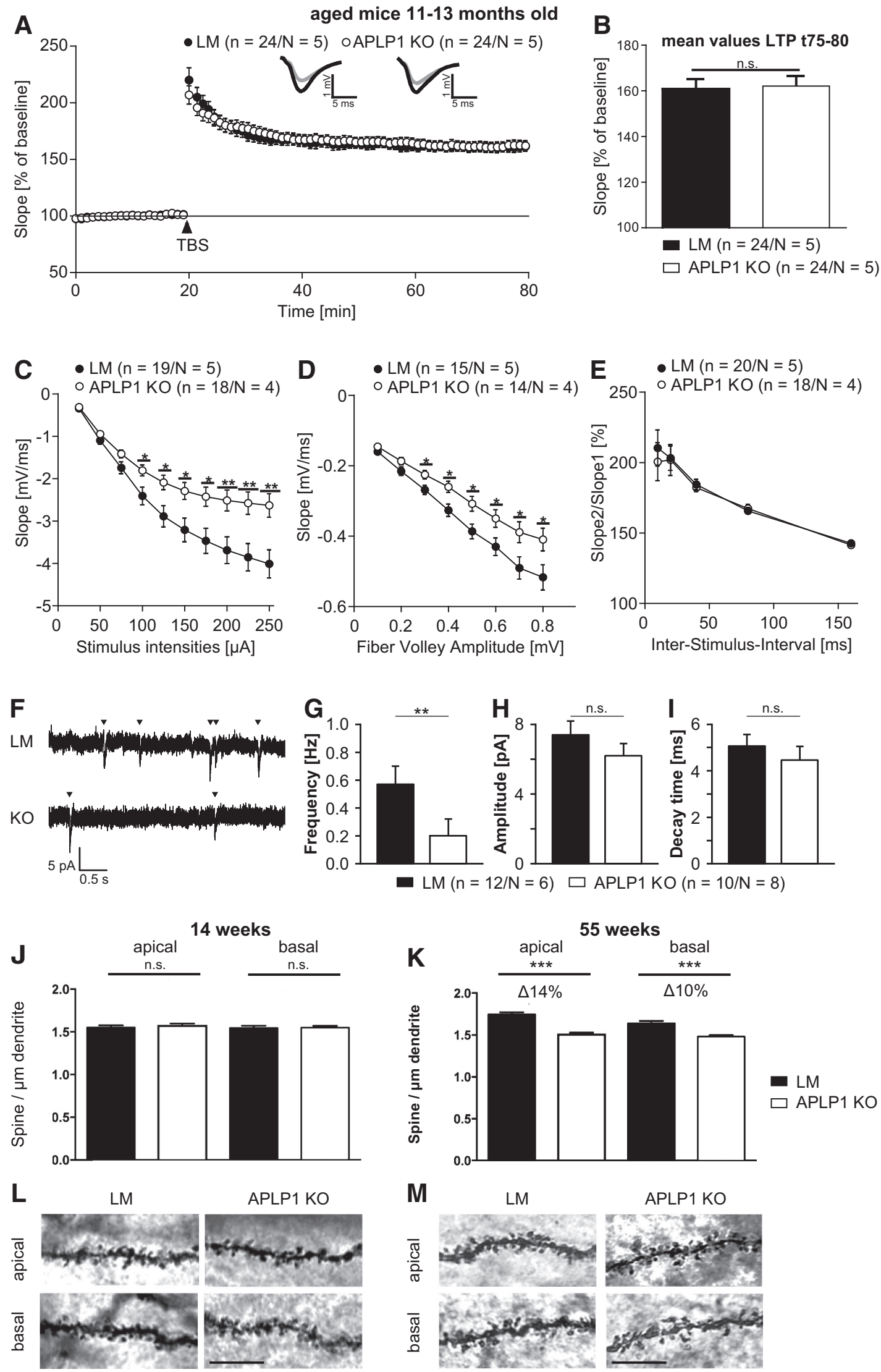

Figure 9. Aged APLP1 KO mice show an age-dependent reduction in spine density, altered postsynaptic function, and reduced mEPP frequency but no LTP deficits. A, LTP was induced in aged mice by applying TBS (10 trains of four pulses at $100 \mathrm{~Hz}$ in a $200 \mathrm{~ms}$ interval, repeated three times) and recorded for 60 min. Data points were averaged over six time points, and error bars indicate the SEM; $n=$ number of recorded slices $/ N=$ number of animals. $B$, Averaged potentiation levels of the last 5 min of LTP were $160.81 \pm 4.29 \%$ in littermate control slices compared to $162.03 \pm$ $4.42 \%$ in APLP1 K0 mice (Student's $t$ test, $p=0.85$ ). C, D, EPSP $(\boldsymbol{C})$ and FV $(\boldsymbol{D})$ measurements indicate altered function of the postsynapse. $\boldsymbol{E}$, PPF (Figure legend continues.) 


\section{Discussion}

Here we performed a systematic comparative analysis of the properties of SAMs for all APP family members.

One characteristic of SAMs is their upregulation during synaptogenesis (Song et al., 1999; Sugita et al., 2001; Biederer et al., 2002; Varoqueaux et al., 2004; Budreck and Scheiffele, 2007; Siddiqui et al., 2013). Indeed, APP/APLPs protein expression that was studied at different developmental stages in mouse cortices revealed an upregulation of both APLP1 and APLP2 starting at P6-P12 (Fig. 1 A,B), which coincides with the onset and peak of synaptogenesis (Semple et al., 2013).

A further characteristic of SAMs is their presynaptic and postsynaptic localization, which allows trans-interaction at synapses. Here we show via synaptosomal fractionations of mouse brains (Fig. 1) as well as immunocytochemical stainings of mouse primary neurons (Figs. 2, 3, 4) that APP, APLP1, and APLP2 are localized to the presynaptic and postsynaptic site. The signal of all APP family members was weak in the PSD fraction when compared to that in synaptosomal fractions, indicating that all APP family members are localized predominantly at the presynapse. However, the observed dendritic immunoreactivity as assessed in primary neurons was more pronounced as the signal detected in the PSD fraction. Possibly, the amount of postsynaptic APP/ APLPs has been underestimated as APP/APLPs might also be present in detergent-soluble extrasynaptic postsynaptic membrane fractions.

We further showed via a coculture assay that besides APP (Wang et al., 2009; Baumkötter et al., 2014; Stahl et al., 2014) also APLP1 and APLP2 are able to induce presynaptic differentiation in contacting axons (Fig. 5). Thus, all members of the mammalian APP family are able to induce presynaptic specializations similar to Neuroligin-Neurexin (used as a positive control; Scheiffele et al., 2000; Dean et al., 2003), and other SAMs (Biederer et al., 2002; Kayser et al., 2006; Kim et al., 2006; Linhoff et al., 2009). Additionally, we could demonstrate that the ability of APLP1 to induce presynaptic differentiation depends on transcellular interaction with APLP1 and/or APLP2 (Fig. 5). At this point, it is unclear whether APP or APLP1 synaptogenic activity depends either on homotypic or heterotypic trans-cellular dimers. It is well possible that only the homotypic interaction of APLP1 is needed for presynaptic differentiation induced by postsynaptic APLP1 and that APLP2 compensates for the absence of presynaptic APLP1. However, as we have shown previously that APP/ APLP1/APLP2 can also form heterotypic trans-cellular interactions (Soba et al., 2005), our observations in APLP1/APLP2 DKO neurons could also rely on APLP1/APLP2 heterotypic trans-cellular interaction. In line with our results, a previous publication doc-

\footnotetext{
(Figure legend continued.) revealed intact presynaptic functionality. $F$, Recording of $\mathrm{mEPSC}$ from pyramidal neurons in the hippocampal CA1 region of aged APLP1 WT and APLP1 K0 mice. $\mathbf{G}-\boldsymbol{I}$, Quantification of frequency $(\boldsymbol{G})$ and amplitude $(\boldsymbol{H})$ of $\mathrm{mEPSC}(\mathrm{s}$ and decay time $(\boldsymbol{I})$. Normally distributed data were assessed by a one-tailed, unpaired (independent) Student's $t$ test, whereas data without normal distribution were assessed via Mann-Whitney $U$ test $\left({ }^{*} p<\right.$ 0.05). J, APLP1 K0 and littermate control animals analyzed at 14 weeks of age did not significantly differ in spine density (unpaired Student's $t$ test, two tailed; $n=40$ neurons/genotype; ns, not significant). Error bars indicate the SEM. $N=5$ animals. $\boldsymbol{K}$, Analysis of 55 -week-old animals revealed significant changes in spine density of apical and basal dendrites between genotypes. APLP1 K0 animals had significantly fewer spines at apical $(\Delta 14 \%)$ and basal $(\Delta 10 \%)$ dendrites compared to LM [unpaired Student's $t$ test, two tailed; $n$ (neurons) $=112$ (APLP1 KO) $\left./ 96(L M),{ }^{* * *} p<0.001\right]$. Error bars indicate the SEM; and $N$ (animals) $=6(\mathrm{LM}) / 7$ (APLP1 KO). $L, M$, Representative images of dendritic branches of apical and basal dendrites of CA1 neurons at $14(\boldsymbol{L})$ and $55(\boldsymbol{M})$ weeks.
}

Table 1. CNS Phenotypes of aged APP family KO mice

\begin{tabular}{llll}
\hline Genotype & Phenotype (aged mice) & Status & Reference \\
\hline APP $^{-1-}$ & Spine density & Reduced & Tyan et al. (2012) \\
& LTP & Impaired & $\begin{array}{c}\text { Seabrook et al. (1999); } \\
\text { Ring et al. (2007); }\end{array}$ \\
& & & Tyan et al. (2012) \\
& Fiber volley/EPSP slope & Unchanged & Tyan et al. (2012) \\
& Paired-pulse facilitation & Unchanged & Tyan et al. (2012) \\
& mEPSC frequency & Not determined & \\
mEPSC amplitude & Not determined & \\
Spine density & Reduced & This article \\
APLP1 ${ }^{-1-}$ & Unchanged & This article \\
& LTP & This article \\
& Fiber volley/EPSP slope & Reduced & This article \\
& Paired-pulse facilitation & Unchanged & This article \\
& mEPSC frequency & Reduced & This article \\
mEPSC amplitude & Unchanged & Midthune et al. (2012) \\
Spine density & Unchanged & Weyer et al. (2011); \\
& LTP & Unchanged & Midthune et al. (2012) \\
& & & Weyer et al. (2011); \\
APLP2 ${ }^{-1-}$ & Miber volley/EPSP slope & Unchanged & Midthune et al. (2012) \\
& Paired-pulse facilitation & Unchanged & Midthune et al. (2012) \\
& mEPSC frequency & Not determined & \\
mEPSC amplitude & Not determined & \\
\hline
\end{tabular}

One-year-old APP, APLP1, and APLP2 K0 mice have been analyzed by different groups. For APLP2, no CNS phenotype has been observed so far. APP KO mice show reduced spine density and impaired LTP. APLP1 KO mice reveal reduced spine density, reduced fiber volley/EPSP slope, and reduced mEPSC frequency.

umented that the APP presynapse inducing the effect is likewise significantly reduced in APP/APLP2 DKO neurons, possibly involving APP/APLP2 homotypic or heterotypic interactions (Wang et al., 2009).

For the synaptic adhesion molecules Neurexin, SynCAM, Calsyntenin3, and APP, binding to X11/MINT is postulated to mediate signaling processes, resulting in presynaptic differentiation (Biederer et al., 2002; Araki et al., 2003; Wang et al., 2009; Muller and Zheng, 2012; Pettem et al., 2013). So far, the binding of APLP1 and APLP2 has been reported for the X11 $\beta /$ MINT2 isoform using a yeast two-hybrid assay (Tomita et al., 1999). Here, we validated the interaction of APLP1 and APLP2 to all members of the X11/MINT family via coimmunoprecipitations (Fig. 8). As X11/MINT proteins are also present postsynaptically (Guillaud et al., 2008), these data suggest a possible role of APP/APLPsX11/MINT interaction at both sides of the synapse.

We reported before stronger trans-interacting properties of APLP1 and APLP2 compared to APP, using a S2 Schneider cell aggregation assay (Soba et al., 2005). However, we could not exclude that the observed S2 cell trans-dimerization was mediated indirectly by other surface proteins, possibly activated by heterologous expression of APP/APLPs. Here, the examination of the APP family trans-interacting properties via an in vitro bead aggregation assay demonstrated direct trans-orientated dimerization of all APP family members, again with increasing trans-dimerization properties for APLP1 > APLP2 > APP (Fig. 6A; Klevanski et al., 2014). In contrast, others have reported trans-coimmunoprecipitation solely for APLP1, but not for APP and APLP2 (Kaden et al., 2009). This is likely explained because the latter remained below detection levels, as APLP1 has a more prominent cell surface localization compared to APP and APLP2 (Figs. 5, 6; Kaden et al., 2009). The reason for this difference in subcellular localization is unknown but might be due to reduced processing of APLP1 at the cell surface or lowered endocytosis rate. Our analyses clearly show that proteolytic conversion of APLP1 is not decreased (Fig. 6 ), whereas the internalization rate of APLP1 is significantly re- 

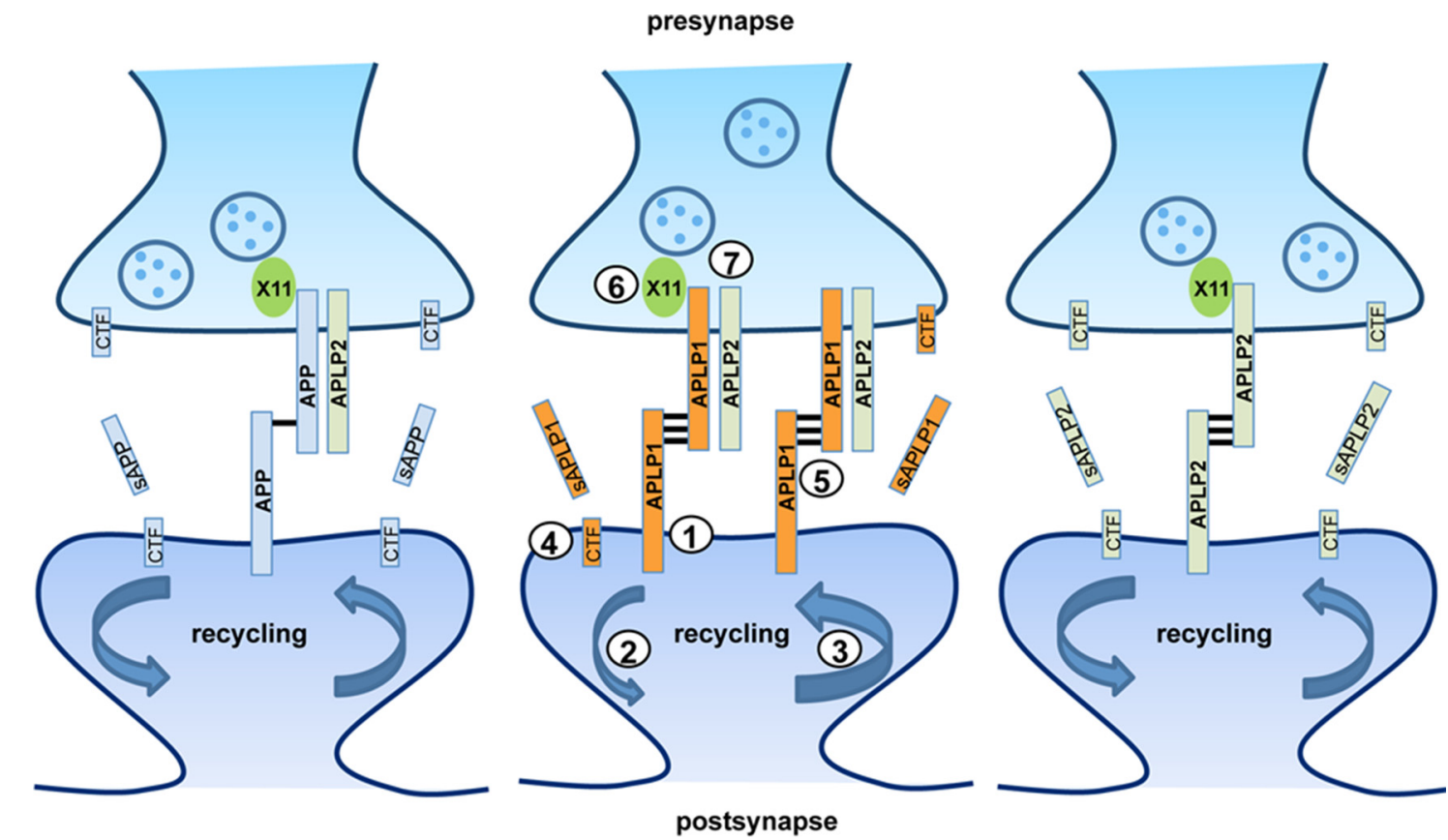

Figure 10. Model of APP gene family members at the synapse. Comparison of several features of APP, APLP1, and APLP2 at the synapse. APLP1 has the strongest presence at the cell surface (1), due to a lower endocytosis rate (2), compared to APP and APLP2 and might travel back to the cell surface via recycling endosomes to a higher extent than APP/APLP2 (3). Furthermore, APLP1 is shedded to a higher extent than APP and APLP2, while the APLP1 (TFs are less produced compared to APP/APLP2 (4). APLP1 and APLP2 show higher trans-binding properties (indicated by three black bars) compared to APP (one black bar; 5). All APP family members have the capacity to induce presynaptic differentiation via trans-synaptic signaling, which is mediated probably via X11/CASK and might link this event to synaptic vesicle exocytosis (6). APP or APLP1 synaptogenic activity depends either on homotypic or heterotypictrans-cellular dimers (Soba et al., 2005; Wang et al., 2009). Notably, APP/APLPs can also heterodimerize in cis-orientation (Soba et al., 2005; Kaden et al., 2009; 7).

duced compared to APP or APLP2 (Fig. 7). Thus, elevated cell surface localization of APLP1 is most likely due to a lowered endocytosis rate. Consistently, an increased half-life time of APLP1 was reported (Gersbacher et al., 2013).

At first, the increased cell surface localization of APLP1 paralleled by elevated sAPLP secretion appears contradictory. However, recent publications showed that APLP1 is predominantly cleaved by BACE1 (Kuhn et al., 2012). Since BACE1 cleavage mainly takes place in endosomes (Vassar et al., 1999), APLP1 might accumulate at the cell surface due to lowered endocytosis and is then most likely cleaved by BACE after internalization and subsequently secreted via the recycling endosomal pathway. However, for the antibody 150 used to detect total sAPLP1, the amounts of detected sAPLP $1 \alpha$ and SAPLP1 $\beta$ are not clear, since all cleavage sites of $\alpha$ - and $\beta$-cleaved APLP1 are still unknown despite one $\beta$-secretase cleavage site at position D568 (Yanagida et al., 2009).

Consistent with the hypothesis that APP/APLPs function as SAMs, APP KO mice show decreased synaptic density and impaired LTP (Tyan et al., 2012). Notably, these deficiencies have only been reported for aged but not for young adult APP KO mice in vivo (Seabrook et al., 1999; Ring et al., 2007; Tyan et al., 2012), indicating that individual APP family members, although upregulated with synaptogenesis in newborn animals (Fig. 1), are not essential for initial synapse formation but possibly are required for maintenance or de novo formation of synapses.

Interestingly, spine density, LTP, paired-pulse facilitation, and basal synaptic transmission in aged APLP2 KO mice are unchanged compared to littermate controls (Weyer et al., 2011; Midthune et al., 2012). This might argue for no essential function of APLP2 at the synapse or, alternatively, might be explained by overlapping synaptic functions of APLP2 with APP or APLP1. In our studies APLP2 showed weak synaptogenic activity in the co- culture assay (Fig. 5) and, most importantly, a redundant function with APLP1 (Fig. 5), similar to the one observed previously with APP (Wang et al., 2009). Furthermore, a recent study (Weyer et al., 2014) could show additional defects in APP/APLP2 DKO mice compared to APP KO mice regarding the dendritic complexity of apical dendrites, suggesting a function of APLP2 for neuronal morphology. Therefore, we conclude that APLP2 belongs to the family of synaptic adhesion molecules as well.

We were able to demonstrate in this study that spine density is decreased in aged APLP1 KO mice, but not in young APLP1 KO mice (Fig. 9), similar to that observed for APP KO mice. In contrast to APP KO mice, we observed in APLP1 KO mice no alterations of LTP in either young or aged mice (Fig. 9). Consistently, a recent study reported no LTP deficit at the perforant pathgranule cell synapses in the dentate gyrus of young adult APLP1deficient mice (Vnencak et al., 2015). This suggests distinct functions of APP and APLP1 at the synapse. Reduced LTP in APP KO mice has been attributed to the loss of $\operatorname{sAPP} \alpha$, which might be involved in NMDA receptor activation (Ring et al., 2007; Weyer et al., 2011). All members of the APP family were shown to interact with NMDA receptors (Cousins et al., 2009, 2015). Therefore, it appears reasonable that SAPLP1 and sAPLP2 might exert different functions at the synapse compared to $\operatorname{sAPP} \alpha$, also after binding to NMDA receptors.

Paired-pulse facilitation was unchanged in aged APLP1 KO mice as well as APP KO mice, indicating intact presynaptic function after loss of APP or APLP1. Interestingly, the strengthening of the fEPSP response to excitatory stimulation (input-output curve) was significantly decreased in aged APLP1 KO mice, while it was unchanged in APP and APLP2 KO mice (Weyer et al., 2011; Midthune et al., 2012; Tyan et al., 2012). Further, APLP1 KO mice exhibit decreased mEPSC frequency. As APLP1 KO mice further show a decreased number of dendritic spines, these data 
strongly suggest that the deficits in basal synaptic transmission and mEPSC frequency are caused by a decreased number of excitatory synapses (Fig. 9, Table 1).

Remarkably, aged APP KO mice show reduced spine density but no difference in extracellular fEPSP values (Tyan et al., 2012). Possibly, the deficits in extracellular fEPSP values in APP KO mice were not detectable, as further distal dendritic segments (300, 330, and $360 \mu \mathrm{m})$ were mainly affected (Weyer et al., 2014). This impact of distance from soma on dendritic spine density was not observed in APLP1 KO mice.

Single-KO mice of other SAMs like LRRTM1, LRRTM3, or LRRTM4; SynCAM1; or Neuroligin 1 show decreased spine numbers already at an early age (between 6 and 23 weeks of age; Takashima et al., 2011; Kwon et al., 2012; Siddiqui et al., 2013; Doengi et al., 2016; Um et al., 2016), indicating different functions in synapse formation, probably more in early stages of initial synapse formation, whereas the members of the APP family might affect more specific mechanisms of structural plasticity in adult stages. Collectively, our findings show that APLP1 has a unique function among the APP family members (Fig. 10) since it is the only family member where aged single-KO mice show impaired basal synaptic transmission while plasticity and LTP are still intact.

Interestingly, different SAM superfamily members have been linked to autism spectrum disorders, mental retardation, and schizophrenia (Jamain et al., 2003; Laumonnier et al., 2004; Francks et al., 2007; Marshall et al., 2008; Yan et al., 2008; Zhiling et al., 2008; Sousa et al., 2010). Thus, based on our data establishing APP, APLP1, and APLP2 as SAMs, it appears reasonable that the APP gene family might be linked to mental disorders other than AD.

\section{References}

Araki Y, Tomita S, Yamaguchi H, Miyagi N, Sumioka A, Kirino Y, Suzuki T (2003) Novel cadherin-related membrane proteins, Alcadeins, enhance the X11-like protein-mediated stabilization of amyloid beta-protein precursor metabolism. J Biol Chem 278:49448-49458. CrossRef Medline

Back S, Haas P, Tschäpe JA, Gruebl T, Kirsch J, Müller U, Beyreuther K, Kins S (2007) Beta-amyloid precursor protein can be transported independent of any sorting signal to the axonal and dendritic compartment. J Neurosci Res 85:2580-2590. CrossRef Medline

Baumkötter F, Wagner K, Eggert S, Wild K, Kins S (2012) Structural aspects and physiological consequences of APP/APLP trans-dimerization. Exp Brain Res 217:389-395. CrossRef Medline

Baumkötter F, Schmidt N, Vargas C, Schilling S, Weber R, Wagner K, Fiedler S, Klug W, Radzimanowski J, Nickolaus S, Keller S, Eggert S, Wild K, Kins S (2014) Amyloid precursor protein dimerization and synaptogenic function depend on copper binding to the growth factor-like domain. J Neurosci 34:11159-11172. CrossRef Medline

Berg EA, Johnson RJ, Leeman SE, Boyd N, Kimerer L, Fine RE (2000) Isolation and characterization of substance P-containing dense core vesicles from rabbit optic nerve and termini. J Neurosci Res 62:830-839. CrossRef Medline

Biederer T, Scheiffele P (2007) Mixed-culture assays for analyzing neuronal synapse formation. Nat Protoc 2:670-676. CrossRef Medline

Biederer T, Sara Y, Mozhayeva M, Atasoy D, Liu X, Kavalali ET, Südhof TC (2002) SynCAM, a synaptic adhesion molecule that drives synapse assembly. Science 297:1525-1531. CrossRef Medline

Bliss TV, Lomo T (1973) Long-lasting potentiation of synaptic transmission in the dentate area of the anaesthetized rabbit following stimulation of the perforant path. J Physiol 232:331-356. CrossRef Medline

Budreck EC, Scheiffele P (2007) Neuroligin-3 is a neuronal adhesion protein at GABAergic and glutamatergic synapses. Eur J Neurosci 26:17381748. CrossRef Medline

Caillé I, Allinquant B, Dupont E, Bouillot C, Langer A, Müller U, Prochiantz A (2004) Soluble form of amyloid precursor protein regulates proliferation of progenitors in the adult subventricular zone. Development 131: 2173-2181. CrossRef Medline
Clarris HJ, Nurcombe V, Small DH, Beyreuther K, Masters CL (1994) Secretion of nerve growth factor from septum stimulates neurite outgrowth and release of the amyloid protein precursor of Alzheimer's disease from hippocampal explants. J Neurosci Res 38:248-258. CrossRef Medline

Coulson EJ, Paliga K, Beyreuther K, Masters CL (2000) What the evolution of the amyloid protein precursor supergene family tells us about its function. Neurochem Int 36:175-184. CrossRef Medline

Cousins SL, Hoey SE, Anne Stephenson F, Perkinton MS (2009) Amyloid precursor protein 695 associates with assembled NR2A- and NR2Bcontaining NMDA receptors to result in the enhancement of their cell surface delivery. J Neurochem 111:1501-1513. CrossRef Medline

Cousins SL, Dai W, Stephenson FA (2015) APLP1 and APLP2, members of the APP family of proteins, behave similarly to APP in that they associate with NMDA receptors and enhance NMDA receptor surface expression. J Neurochem 133:879-885. CrossRef Medline

Dalva MB, McClelland AC, Kayser MS (2007) Cell adhesion molecules: signalling functions at the synapse. Nat Rev Neurosci 8:206-220. CrossRef Medline

Dean C, Scholl FG, Choih J, DeMaria S, Berger J, Isacoff E, Scheiffele P (2003) Neurexin mediates the assembly of presynaptic terminals. Nat Neurosci 6:708-716. CrossRef Medline

De Felipe J, Marco P, Fairén A, Jones EG (1997) Inhibitory synaptogenesis in mouse somatosensory cortex. Cereb Cortex 7:619-634. CrossRef Medline

Doengi M, Krupp AJ, Körber N, Stein V (2016) SynCAM 1 improves survival of adult-born neurons by accelerating synapse maturation. Hippocampus 26:319-328. CrossRef Medline

Eggert S, Paliga K, Soba P, Evin G, Masters CL, Weidemann A, Beyreuther K (2004) The proteolytic processing of the amyloid precursor protein gene family members APLP-1 and APLP-2 involves alpha-, beta-, gamma-, and epsilon-like cleavages: modulation of APLP-1 processing by n-glycosylation. J Biol Chem 279:18146-18156. CrossRef Medline

Fol R, Braudeau J, Ludewig S, Abel T, Weyer SW, Roederer JP, Brod F, Audrain M, Bemelmans AP, Buchholz CJ, Korte M, Cartier N, Muller UC (2016) Viral gene transfer of APPs $\alpha$ rescues synaptic failure in an Alzheimer's disease mouse model. Acta Neuropathol 131:247-266. Medline

Francks C, Maegawa S, Laurén J, Abrahams BS, Velayos-Baeza A, Medland SE, Colella S, Groszer M, McAuley EZ, Caffrey TM, Timmusk T, Pruunsild P, Koppel I, Lind PA, Matsumoto-Itaba N, Nicod J, Xiong L, Joober R, Enard W, Krinsky B, et al (2007) LRRTM1 on chromosome 2p12 is a maternally suppressed gene that is associated paternally with handedness and schizophrenia. Mol Psychiatry 12:1129-1139, 1057. CrossRef Medline

Gersbacher MT, Goodger ZV, Trutzel A, Bundschuh D, Nitsch RM, Konietzko U (2013) Turnover of amyloid precursor protein family members determines their nuclear signaling capability. PLoS One 8:e69363. CrossRef Medline

Guillaud L, Wong R, Hirokawa N (2008) Disruption of KIF17-Mint1 interaction by CaMKII-dependent phosphorylation: a molecular model of kinesin-cargo release. Nat Cell Biol 10:19-29. CrossRef Medline

Hardy J, Selkoe DJ (2002) The amyloid hypothesis of Alzheimer's disease: progress and problems on the road to therapeutics. Science 297:353-356. CrossRef Medline

Heber S, Herms J, Gajic V, Hainfellner J, Aguzzi A, Rülicke T, von Kretzschmar H, von Koch C, Sisodia S, Tremml P, Lipp HP, Wolfer DP, Müller U (2000) Mice with combined gene knock-outs reveal essential and partially redundant functions of amyloid precursor protein family members. J Neurosci 20:7951-7963. Medline

Herring BE, Nicoll RA (2016) Long-term potentiation: from CaMKII to AMPA receptor trafficking. Annu Rev Physiol 78:351-365. CrossRef Medline

Hick M, Herrmann U, Weyer SW, Mallm JP, Tschape JA, Borgers M, Mercken M, Roth FC, Draguhn A, Slomianka L, Wolfer DP, Korte M, Muller UC (2015) Acute function of secreted amyloid precursor protein fragment APPs $\alpha$ in synaptic plasticity. Acta Neuropathol 129:21-37. Medline

Hoe HS, Fu Z, Makarova A, Lee JY, Lu C, Feng L, Pajoohesh-Ganji A, Matsuoka Y, Hyman BT, Ehlers MD, Vicini S, Pak DT, Rebeck GW (2009) The effects of amyloid precursor protein on postsynaptic composition and activity. J Biol Chem 284:8495-8506. CrossRef Medline

Jacobsen KT, Iverfeldt K (2009) Amyloid precursor protein and its homologues: a family of proteolysis-dependent receptors. Cell Mol Life Sci 66:2299-2318. CrossRef Medline

Jamain S, Quach H, Betancur C, Råstam M, Colineaux C, Gillberg IC, Sod- 
erstrom H, Giros B, Leboyer M, Gillberg C, Bourgeron T (2003) Mutations of the X-linked genes encoding neuroligins NLGN3 and NLGN4 are associated with autism. Nat Genet 34:27-29. CrossRef Medline

Kaden D, Voigt P, Munter LM, Bobowski KD, Schaefer M, Multhaup G (2009) Subcellular localization and dimerization of APLP1 are strikingly different from APP and APLP2. J Cell Sci 122:368-377. CrossRef Medline

Kayser MS, McClelland AC, Hughes EG, Dalva MB (2006) Intracellular and trans-synaptic regulation of glutamatergic synaptogenesis by EphB receptors. J Neurosci 26:12152-12164. CrossRef Medline

Kim S, Burette A, Chung HS, Kwon SK, Woo J, Lee HW, Kim K, Kim H, Weinberg RJ, Kim E (2006) NGL family PSD-95-interacting adhesion molecules regulate excitatory synapse formation. Nat Neurosci 9:12941301. CrossRef Medline

Kim TW, Wu K, Xu JL, McAuliffe G, Tanzi RE, Wasco W, Black IB (1995) Selective localization of amyloid precursor-like protein 1 in the cerebral cortex postsynaptic density. Brain Res Mol Brain Res 32:36-44. CrossRef Medline

Klevanski M, Saar M, Baumkötter F, Weyer SW, Kins S, Müller UC (2014) Differential role of APP and APLPs for neuromuscular synaptic morphology and function. Mol Cell Neurosci 61:201-210. CrossRef Medline

Koo EH, Squazzo SL (1994) Evidence that production and release of amyloid beta-protein involves the endocytic pathway. J Biol Chem 269: 17386-17389. Medline

Kuhn PH, Koroniak K, Hogl S, Colombo A, Zeitschel U, Willem M, Volbracht C, Schepers U, Imhof A, Hoffmeister A, Haass C, Roßner S, Bräse S, Lichtenthaler SF (2012) Secretome protein enrichment identifies physiological BACE1 protease substrates in neurons. EMBO J 31:31573168. CrossRef Medline

Kullmann JA, Neumeyer A, Gurniak CB, Friauf E, Witke W, Rust MB (2011) Profilin1 is required for glial cell adhesion and radial migration of cerebellar granule neurons. EMBO Rep 13:75-82. CrossRef Medline

Kwon HB, Kozorovitskiy Y, Oh WJ, Peixoto RT, Akhtar N, Saulnier JL, Gu C, Sabatini BL (2012) Neuroligin-1-dependent competition regulates cortical synaptogenesis and synapse number. Nat Neurosci 15:1667-1674. CrossRef Medline

Laßek M, Weingarten J, Einsfelder U, Brendel P, Müller U, Volknandt W (2013) Amyloid precursor proteins are constituents of the presynaptic active zone. J Neurochem 127:48-56. CrossRef Medline

Laumonnier F, Bonnet-Brilhault F, Gomot M, Blanc R, David A, Moizard MP, Raynaud M, Ronce N, Lemonnier E, Calvas P, Laudier B, Chelly J, Fryns JP, Ropers HH, Hamel BC, Andres C, Barthélémy C, Moraine C, Briault S (2004) X-linked mental retardation and autism are associated with a mutation in the NLGN4 gene, a member of the neuroligin family. Am J Hum Genet 74:552-557. CrossRef Medline

Lee KJ, Moussa CE, Lee Y, Sung Y, Howell BW, Turner RS, Pak DT, Hoe HS (2010) Beta amyloid-independent role of amyloid precursor protein in generation and maintenance of dendritic spines. Neuroscience 169:344356. CrossRef Medline

Li Q, Südhof TC (2004) Cleavage of amyloid-beta precursor protein and amyloid-beta precursor-like protein by BACE 1. J Biol Chem 279:1054210550. CrossRef Medline

Linhoff MW, Laurén J, Cassidy RM, Dobie FA, Takahashi H, Nygaard HB, Airaksinen MS, Strittmatter SM, Craig AM (2009) An unbiased expression screen for synaptogenic proteins identifies the LRRTM protein family as synaptic organizers. Neuron 61:734-749. CrossRef Medline

Lorent K, Overbergh L, Moechars D, De Strooper B, Van Leuven F, Van den Berghe H (1995) Expression in mouse embryos and in adult mouse brain of three members of the amyloid precursor protein family, of the alpha-2-macroglobulin receptor/low density lipoprotein receptor-related protein and of its ligands apolipoprotein E, lipoprotein lipase, alpha-2macroglobulin and the 40,000 molecular weight receptor-associated protein. Neuroscience 65:1009-1025. CrossRef Medline

Lyckman AW, Confaloni AM, Thinakaran G, Sisodia SS, Moya KL (1998) Post-translational processing and turnover kinetics of presynaptically targeted amyloid precursor superfamily proteins in the central nervous system. J Biol Chem 273:11100-11106. CrossRef Medline

Marshall CR, Noor A, Vincent JB, Lionel AC, Feuk L, Skaug J, Shago M, Moessner R, Pinto D, Ren Y, Thiruvahindrapduram B, Fiebig A, Schreiber S, Friedman J, Ketelaars CE, Vos YJ, Ficicioglu C, Kirkpatrick S, Nicolson $\mathrm{R}$, Sloman L, et al (2008) Structural variation of chromosomes in autism spectrum disorder. Am J Hum Genet 82:477-488. CrossRef Medline

Midthune B, Tyan SH, Walsh JJ, Sarsoza F, Eggert S, Hof PR, Dickstein DL,
Koo EH (2012) Deletion of the amyloid precursor-like protein 2 (APLP2) does not affect hippocampal neuron morphology or function. Mol Cell Neurosci 49:448-455. CrossRef Medline

Moritz CP, Marz SX, Reiss R, Schulenborg T, Friauf E (2014) Epicocconone staining: a powerful loading control for Western blots. Proteomics 14: 162-168. CrossRef Medline

Muller UC, Zheng H (2012) Physiological functions of APP family proteins. Cold Spring Harbor Perspect Med 2:a006288. CrossRef Medline

Müller U, Cristina N, Li ZW, Wolfer DP, Lipp HP, Rulicke T, Brandner S, Aguzzi A, Weissmann C (1994) Behavioral and anatomical deficits in mice homozygous for a modified beta-amyloid precursor protein gene. Cell 79:755-765. CrossRef Medline

Müller UC, Deller T, Korte M (2017) Not just amyloid: physiological functions of the amyloid precursor protein family. Nat Rev Neurosci 18:281298. CrossRef

Paliga K, Peraus G, Kreger S, Dürrwang U, Hesse L, Multhaup G, Masters CL, Beyreuther K, Weidemann A (1997) Human amyloid precursor-like protein 1-cDNA cloning, ectopic expression in COS-7 cells and identification of soluble forms in the cerebrospinal fluid. Eur J Biochem 250:354363. CrossRef Medline

Pettem KL, Yokomaku D, Luo L, Linhoff MW, Prasad T, Connor SA, Siddiqui TJ, Kawabe H, Chen F, Zhang L, Rudenko G, Wang YT, Brose N, Craig AM (2013) The specific alpha-neurexin interactor calsyntenin-3 promotes excitatory and inhibitory synapse development. Neuron 80:113128. CrossRef Medline

Phinney AL, Calhoun ME, Wolfer DP, Lipp HP, Zheng H, Jucker M (1999) No hippocampal neuron or synaptic bouton loss in learning-impaired aged beta-amyloid precursor protein-null mice. Neuroscience 90:12071216. CrossRef Medline

Ring S, Weyer SW, Kilian SB, Waldron E, Pietrzik CU, Filippov MA, Herms J, Buchholz C, Eckman CB, Korte M, Wolfer DP, Müller UC (2007) The secreted $\beta$-amyloid precursor protein ectodomain APPs $\alpha$ is sufficient to rescue the anatomical, behavioral, and electrophysiological abnormalities of APP-deficient mice. J Neurosci 27:7817-7826. CrossRef Medline

Sandbrink R, Masters CL, Beyreuther K (1994) Beta A4-amyloid protein precursor mRNA isoforms without exon 15 are ubiquitously expressed in rat tissues including brain, but not in neurons. J Biol Chem 269:1510 1517. Medline

Sandbrink R, Masters CL, Beyreuther K (1996) APP gene family. Alternative splicing generates functionally related isoforms. Ann N Y Acad Sci 777: 281-287. CrossRef Medline

Scheiffele P, Fan J, Choih J, Fetter R, Serafini T (2000) Neuroligin expressed in nonneuronal cells triggers presynaptic development in contacting axons. Cell 101:657-669. CrossRef Medline

Seabrook GR, Smith DW, Bowery BJ, Easter A, Reynolds T, Fitzjohn SM, Morton RA, Zheng H, Dawson GR, Sirinathsinghji DJ, Davies CH, Collingridge GL, Hill RG (1999) Mechanisms contributing to the deficits in hippocampal synaptic plasticity in mice lacking amyloid precursor protein. Neuropharmacology 38:349-359. CrossRef Medline

Semple BD, Blomgren K, Gimlin K, Ferriero DM, Noble LJ-Haeusslein (2013) Brain development in rodents and humans: identifying benchmarks of maturation and vulnerability to injury across species. Prog Neurobiol 106-107:1-16. CrossRef

Siddiqui TJ, Craig AM (2011) Synaptic organizing complexes. Curr Opin Neurobiol 21:132-143. CrossRef Medline

Siddiqui TJ, Tari PK, Connor SA, Zhang P, Dobie FA, She K, Kawabe H, Wang YT, Brose N, Craig AM (2013) An LRRTM4-HSPG complex mediates excitatory synapse development on dentate gyrus granule cells. Neuron 79:680-695. CrossRef Medline

Soba P, Eggert S, Wagner K, Zentgraf H, Siehl K, Kreger S, Löwer A, Langer A, Merdes G, Paro R, Masters CL, Müller U, Kins S, Beyreuther K (2005) Homo- and heterodimerization of APP family members promotes intercellular adhesion. EMBO J 24:3624-3634. CrossRef Medline

Song JY, Ichtchenko K, Südhof TC, Brose N (1999) Neuroligin 1 is a postsynaptic cell-adhesion molecule of excitatory synapses. Proc Natl Acad Sci U S A 96:1100-1105. CrossRef Medline

Sousa I, Clark TG, Holt R, Pagnamenta AT, Mulder EJ, Minderaa RB, Bailey AJ, Battaglia A, Klauck SM, Poustka F, Monaco AP (2010) Polymorphisms in leucine-rich repeat genes are associated with autism spectrum disorder susceptibility in populations of European ancestry. Mol Autism 1:7. CrossRef Medline

Stahl R, Schilling S, Soba P, Rupp C, Hartmann T, Wagner K, Merdes G, 
Eggert S, Kins S (2014) Shedding of APP limits its synaptogenic activity and cell adhesion properties. Front Cell Neurosci 8:410. CrossRef Medline

Sugita S, Saito F, Tang J, Satz J, Campbell K, Südhof TC (2001) A stoichiometric complex of neurexins and dystroglycan in brain. J Cell Biol 154: 435-445. CrossRef Medline

Sumioka A, Saito Y, Sakuma M, Araki Y, Yamamoto T, Suzuki T (2008) The X11L/X11beta/MINT2 and X11L2/X11gamma/MINT3 scaffold proteins shuttle between the nucleus and cytoplasm. Exp Cell Res 314:1155-1162. CrossRef Medline

Takashima N, Odaka YS, Sakoori K, Akagi T, Hashikawa T, Morimura N, Yamada K, Aruga J (2011) Impaired cognitive function and altered hippocampal synapse morphology in mice lacking Lrrtm1, a gene associated with schizophrenia. PLoS One 6:e22716. CrossRef Medline

Tomita S, Ozaki T, Taru H, Oguchi S, Takeda S, Yagi Y, Sakiyama S, Kirino Y, Suzuki T (1999) Interaction of a neuron-specific protein containing PDZ domains with Alzheimer's amyloid precursor protein. J Biol Chem 274:2243-2254. CrossRef Medline

Tyan SH, Koo EH (2015) New tricks from an old dog: another synaptotoxic fragment from APP. Cell Res 25:1185-1186. CrossRef Medline

Tyan SH, Shih AY, Walsh JJ, Maruyama H, Sarsoza F, Ku L, Eggert S, Hof PR, Koo EH, Dickstein DL (2012) Amyloid precursor protein (APP) regulates synaptic structure and function. Mol Cell Neurosci 51:43-52. CrossRef Medline

Um JW, Choi TY, Kang H, Cho YS, Choii G, Uvarov P, Park D, Jeong D, Jeon S, Lee D, Kim H, Lee SH, Bae YC, Choi SY, Airaksinen MS, Ko J (2016) LRRTM3 regulates excitatory synapse development through alternative splicing and neurexin binding. Cell Rep 14:808-822. CrossRef Medline

Varoqueaux F, Jamain S, Brose N (2004) Neuroligin 2 is exclusively localized to inhibitory synapses. Eur J Cell Biol 83:449-456. CrossRef Medline

Vassar R, Bennett BD, Babu-Khan S, Kahn S, Mendiaz EA, Denis P, Teplow DB, Ross S, Amarante P, Loeloff R, Luo Y, Fisher S, Fuller J, Edenson S, Lile J, Jarosinski MA, Biere AL, Curran E, Burgess T, Louis JC, et al (1999) Beta-secretase cleavage of Alzheimer's amyloid precursor protein by the transmembrane aspartic protease BACE. Science 286:735-741. CrossRef Medline

Vella LJ, Cappai R (2012) Identification of a novel amyloid precursor protein processing pathway that generates secreted $\mathrm{N}$-terminal fragments. FASEB J 26:2930-2940. CrossRef Medline

Vnencak M, Paul MH, Hick M, Schwarzacher SW, Del Turco D, Müller UC, Deller T, Jedlicka P (2015) Deletion of the amyloid precursor-like protein 1 (APLP1) enhances excitatory synaptic transmission, reduces network inhibition but does not impair synaptic plasticity in the mouse dentate gyrus. J Comp Neurol 523:1717-1729. CrossRef Medline

von Koch CS, Zheng H, Chen H, Trumbauer M, Thinakaran G, van der Ploeg LH, Price DL, Sisodia SS (1997) Generation of APLP2 KO mice and early postnatal lethality in APLP2/APP double KO mice. Neurobiol Aging 18:661-669. CrossRef Medline

Walsh DM, Minogue AM, Sala Frigerio C, Fadeeva JV, Wasco W, Selkoe DJ (2007) The APP family of proteins: similarities and differences. Biochem Soc Trans 35:416-420. CrossRef Medline

Wang P, Yang G, Mosier DR, Chang P, Zaidi T, Gong YD, Zhao NM, Dominguez B, Lee KF, Gan WB, Zheng H (2005) Defective neuromuscular synapses in mice lacking amyloid precursor protein (APP) and APP-Like protein 2. J Neurosci 25:1219-1225. CrossRef Medline

Wang Z, Wang B, Yang L, Guo Q, Aithmitti N, Songyang Z, Zheng H (2009) Presynaptic and postsynaptic interaction of the amyloid precursor protein promotes peripheral and central synaptogenesis. J Neurosci 29: 10788-10801. CrossRef Medline

Wasco W, Bupp K, Magendantz M, Gusella JF, Tanzi RE, Solomon F (1992) Identification of a mouse brain cDNA that encodes a protein related to the Alzheimer disease-associated amyloid beta protein precursor. Proc Natl Acad Sci U S A 89:10758-10762. CrossRef Medline

Wasco W, Gurubhagavatula S, Paradis MD, Romano DM, Sisodia SS, Hyman BT, Neve RL, Tanzi RE (1993) Isolation and characterization of APLP2 encoding a homologue of the Alzheimer's associated amyloid beta protein precursor. Nat Genet 5:95-100. CrossRef Medline

Weyer SW, Klevanski M, Delekate A, Voikar V, Aydin D, Hick M, Filippov M, Drost N, Schaller KL, Saar M, Vogt MA, Gass P, Samanta A, Jäschke A, Korte M, Wolfer DP, Caldwell JH, Müller UC (2011) APP and APLP2 are essential at PNS and CNS synapses for transmission, spatial learning and LTP. EMBO J 30:2266-2280. CrossRef Medline

Weyer SW, Zagrebelsky M, Herrmann U, Hick M, Ganss L, Gobbert J, Gruber M, Altmann C, Korte M, Deller T, Müller UC (2014) Comparative analysis of single and combined APP/APLP knockouts reveals reduced spine density in APP-KO mice that is prevented by APPsalpha expression. Acta Neuropathol Commun 2:36. CrossRef Medline

Yanagida K, Okochi M, Tagami S, Nakayama T, Kodama TS, Nishitomi K, Jiang J, Mori K, Tatsumi S, Arai T, Ikeuchi T, Kasuga K, Tokuda T, Kondo M, Ikeda M, Deguchi K, Kazui H, Tanaka T, Morihara T, Hashimoto R, et al (2009) The 28-amino acid form of an APLP1-derived Abeta-like peptide is a surrogate marker for Abeta42 production in the central nervous system. EMBO Mol Med 1:223-235. CrossRef Medline

Yan J, Noltner K, Feng J, Li W, Schroer R, Skinner C, Zeng W, Schwartz CE, Sommer SS (2008) Neurexin lalpha structural variants associated with autism. Neurosci Lett 438:368-370. CrossRef Medline

Zhiling Y, Fujita E, Tanabe Y, Yamagata T, Momoi T, Momoi MY (2008) Mutations in the gene encoding CADM1 are associated with autism spectrum disorder. Biochem Biophys Res Commun 377:926-929. CrossRef Medline 